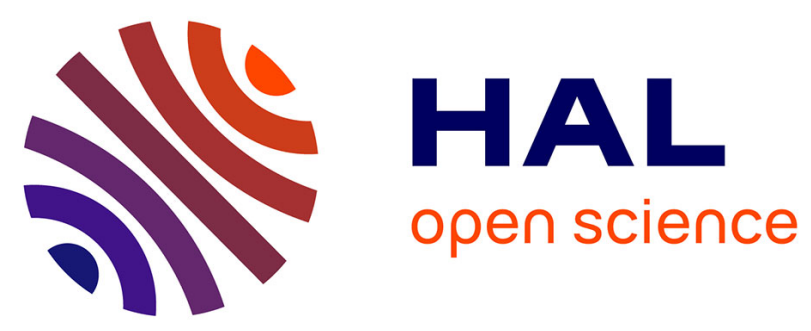

\title{
Chemical stability of caesium iodide deposits in air/steam atmosphere
}

Dorel Obada, Houssam Hijazi, Jean-François Paul, Laurent Gasnot, Anne Cecile Gregoire, Anne Sophie Mamede, Laurent Cantrel

\section{To cite this version:}

Dorel Obada, Houssam Hijazi, Jean-François Paul, Laurent Gasnot, Anne Cecile Gregoire, et al.. Chemical stability of caesium iodide deposits in air/steam atmosphere. Journal of Hazardous Materials, 2020, 409, pp.124519. 10.1016/j.jhazmat.2020.124519 . hal-03539663

\section{HAL Id: hal-03539663 https://hal.science/hal-03539663}

Submitted on 21 Jan 2022

HAL is a multi-disciplinary open access archive for the deposit and dissemination of scientific research documents, whether they are published or not. The documents may come from teaching and research institutions in France or abroad, or from public or private research centers.
L'archive ouverte pluridisciplinaire HAL, est destinée au dépôt et à la diffusion de documents scientifiques de niveau recherche, publiés ou non, émanant des établissements d'enseignement et de recherche français ou étrangers, des laboratoires publics ou privés.

\section{(1) (1) $\$$}

Distributed under a Creative Commons Attribution - NonCommercial - NoDerivatives| 4.0 


\title{
Chemical stability of caesium iodide deposits in air/steam atmosphere
}

D. Obada ${ }^{a, b} ;$ H. Hijazi ${ }^{a, b}$, J.-F. Paul ${ }^{b}$, L. Gasnot ${ }^{c}$, A.-C. Grégoire ${ }^{a}$, A.-S. Mamede ${ }^{b}$, L. Cantrel $^{a}$

a Institut de Radioprotection et de Sûreté Nucléaire, Pôle Sûreté Nucléaire, CEN Cadarache, Saint Paul lez Durance F-13115, France

${ }^{b}$ Univ. Lille, CNRS, Centrale Lille, Univ. Artois, UMR 8181 - UCCS - Unité de Catalyse et Chimie du Solide, F-59000 Lille, France

c Univ. Lille, CNRS, UMR 8522 - PC2A - Physicochimie des Processus de Combustion et de l'Atmosphère, F-59000 Lille, France

\begin{abstract}
lodine compounds that may be released in case of severe nuclear accident will have important radiotoxicity if they are disseminated in air. One of the most important iodine species is CsI that is deposited on the surfaces of the reactor coolant system. However, depending on the conditions, Csl can volatilize or react with oxidants to produce $\mathrm{I}_{2(\mathrm{~g})}$. Theoretical and experimental studies demonstrate that the oxidation of iodide depends on the temperature and in the presence of oxidants in the gas. It is also slightly influenced by the crystallinity of the CsI particles and the nature of the support. In case of a high temperature deposition, the iodine release started at temperature lower than $300^{\circ} \mathrm{C}$. For the Csl vapour and aerosol depositions, the iodine is detected only at temperature above $450^{\circ} \mathrm{C}$ and become very important above $550^{\circ} \mathrm{C}$.
\end{abstract}

\section{Key words}

Fission products, re-vaporization, severe nuclear accident, DFT calculations.

\section{Introduction}

In case of a severe accident (SA) occurring in a Pressurized Water Reactor (PWR), volatile radioactive fission products (FPs), such as caesium and iodine, are released from the degraded fuel. They are transported through the reactor coolant system (RCS) and the containment building and can be released into the environment via direct leakages of the nuclear containment and/or by the containment venting process in case of overpressure. As a result, these FPs can contribute to the radiological consequences for the population in the short term for iodine and the long-term for caesium.

In order to simulate an accidental scenario and predict the release of FPs, the ASTEC (Accident Source Term Evaluation Code) calculation code has been developed by the French Institute for Radiological Protection and Nuclear Safety (IRSN). In order to get predictive simulations[1], a comprehensive knowledge of all the phenomena occurring in a PWR during a severe accident situation is necessary. Considerable advances have been made in the field of understanding the behaviour of volatile FPs such as iodine after their release from the damaged core, thanks to experimental programs such as Phébus-FP [2] and other experimental works devoted to FP behaviour[3] and subsequent modelling works. 
Nevertheless, some phenomena are not accounted foryet by the simulation tools and it is difficult to predict their outcome, mostly because of a lack of experimental and/or theoretical data. It is the case with the re-vaporization of FPs deposits from the surface of the RCS. FPs will form deposits on the surface of the RCS by different mechanisms, the most important of which are vapour condensation and thermophoresis as predicted by Hidaka et al. [4] and Maruyama et al. [5], as well as gravity deposition. The Phébus-FP experimental program has shown that Cs and I can significantly deposits in the RCS [6]. The main identified iodine compounds is CsI - resulting from condensation of CsI vapours in the $600-650^{\circ} \mathrm{C}$ temperature range (as expected from thermodynamic calculations and simulation with severe accident software as the ASTEC code [1]). Other condensed iodine form were identified too, but their nature could not be fully unravell ed -they are expected to be metalliciodide of control rod material ( $\mathrm{Cd}$ or $\mathrm{Ag}$ ). Moreover, it was determined from Phébus tests, that $\mathrm{Cs}$ remobilization can reach up to $75 \%$ of the initial deposit in certain conditions [2]. More recently, in the aftermath of the Fukushima Daiichi accident, delayed releases for iodine and caesium have been detected several days after the accident [7] [8], and are believed to be related to the chemical revaporization of caesium and iodine containing deposits.

In the past several attempts have been made to understand the phenomenon of FPs remobilization. As a follow-up of the Phebus-FP tests, a series of research programs have been launched by several institutions. The studies focused mainly on the re-vaporization of caesium in a wide range of temperature and carrier gas conditions; iodine behaviour, for its part, was less studied. The studied precursor was mostly CsOH [8-12], less frequently CsI [10, 13, 14-16].

As for caesium, AEA-T [9] studied the re-vaporization of synthetic $\mathrm{CsOH}$ deposits in a flow reactor at temperatures reaching up to $1100^{\circ} \mathrm{C}$, analysing the mass balance and surface interaction between caesium and the substrate made of $304 \mathrm{SS}$ steel. Auvinen et al. [10] have studied the vaporization of $\mathrm{CsOH}$ and $\mathrm{Csl}$ powders from stainless steel crucibles. The samples were traced with radioactive Cs $\left({ }^{134} \mathrm{Cs}\right.$ or $\left.{ }^{137} \mathrm{Cs}\right)$, which allowed establishing a release kinetics thanks to $\gamma$-spectrometry measurements. The two studies used steam as carrier gas and it was established that the Cs revaporization starts at $\approx 500^{\circ} \mathrm{C}$. Bottomley et al. [11] and Knebel et al. [12] performed online $\gamma$ spectrometry measurements of ${ }^{137} \mathrm{Cs}$ from deposits issued from the Phebus-FP tests (vapour deposition at temperatures up to $700^{\circ} \mathrm{C}$ ), which are as realistic as possible. However the initial composition of the deposits, as well as the surface state of the stainless steel substrate is not well defined. The results show that in steam Cs is released starting from $550^{\circ} \mathrm{C}$, whereas in air atmosphere the release occurs at a lower temperature, as low as $300^{\circ} \mathrm{C}$.

The studies dealing with CsI were aimed at investigating conditions leading to CsI decomposition and subsequent gaseous iodine releases. Experiments performed by Kalilainen et al. [13] allowed a better understanding of the re-vaporized Cs and I distribution between gaseous and aerosol forms, thanks to the use of liquid scrubbers and filters adapted for each type of material. It was found that up to $27 \%$ of initial iodine content is released in gaseous form in an argon/steam atmosphere, and that it decreases with the introduction of hydrogen in the carrier gas. Shibazaki et al. [14] performed tests with Csl in steam and concluded that it starts re-vaporizing at $\approx 490^{\circ} \mathrm{C}$ and is released mainly as Csl. Berdonosov et al. [15] [16] conducted small-scale tests to further study the chemical nature of the released gaseous iodine. By heating $\mathrm{Csl}$ in air up to $1250^{\circ} \mathrm{C}$, the formation of gaseous molecular iodine $I_{2}$ has been observed, the higher the temperature the larger the amount. Kulyukhin et al. [17] studied the hydrolysis of $\mathrm{Csl}$ in presence of molecular oxygen in the $630-1300^{\circ} \mathrm{C}$ range and the 
formation of $\mathrm{I}_{2}$ has been also confirmed, indirectly. However, some key parameters were not fully investigated in those studies. For instance, the FP deposit-substrate interaction was not always taken into account. Indeed, if some studies featured stainless steel substrates [10,13] the initial surface state is not documented. Some studies featured even substrates not representative of the RCS (glass or platinum [14-16], alumina [10]). Secondly, the process of CsI deposition was not al ways examined as most of studies were performed with commercial Csl powder; Csl vapour and aerosol deposition were only considered in [13]. Finally, the influence of carrier gas composition and thermal conditions on re-vaporization were not fully investigated: most of studies considered steam or steam/hydrogen atmospheres which are more representative of early degradation phase during $\mathrm{SA}$, whereas air was only considered in [14-16], but in the latter case, the thermal treatment (flash heating up to $1250^{\circ} \mathrm{C}$ ) seems unrealistic regarding late phase SA conditions.

From the theoretical point of view, to the best of our knowledge, the revaporisation and the chemical reactivity of Csl aerosols had only been studied by $\mathrm{H}$. Hijazi ([18]). The other theoretical studies in a nuclear frame focused on the gas reactivity of iodine species or on chemical stability/reactivity of caesium species ([19] [20] [21] [22] [23] [24] [25] [26] [27]. Severe accident simulations in the RCS are based on chemical equilibrium in gas phase thus ab initio computations were performed on the speciation at the equilibrium of the compound containing iodide or caesium. The gas inorganic chemistry involves mainly molecular iodine $\left(I_{2}\right)$, monoatomic iodine radicals $\left(I^{\circ}\right)$ and iodine oxides $\left(\mathrm{IO}_{\mathrm{x}}\right)$. The conversion between the species are fast and are favoured by oxidants such as nitrogen oxide and by visible light or radiation. The interaction with water occurs through the formation of hydrogen bonds and hydrogen transfer between acidic and radical species. The reactivity of caesium species in the gas phase has not been studied extensively. The reaction between $\mathrm{CsO}$ and $\mathrm{H}_{2}$ have been investigated by Louis at al. [28]. Based on all these studies, it is possible to estimate the concentrations of some iodine and caesium species in the gas phase depending on the experimental conditions [29].

In conclusion, data on caesium and more particularly on gaseous iodine re-vaporization are too scarce and remain to be confirmed in more representative conditions to build an appropriate modelling.

The work presented here was aimed at fill in the gap in knowledge on CsI re-vaporization in conditions as representative as possible of a late phase of a SA scenario, in terms of: i/ substrate nature (pre-oxidized $304 \mathrm{~L}$ and $316 \mathrm{~L}$ stainless steel which correspond to RCS steel composition) ii/ deposit generation (reproducing the different temperature deposition processes as in [13]: high temperature deposition, vapour condensation and finally aerosol impaction with realistic deposited amounts $\sim$ i.e. few $\mathrm{mg} / \mathrm{cm}^{2}$ ) iii/ re-vaporization thermal conditions (with heating up to $750{ }^{\circ} \mathrm{C}$ ), iv/ presence of air (steam/air mixtures), since air is susceptible to penetrate in the RCS in case of an airingress accidental scenario[30]. We aimed at a better assessment of gaseous iodine release with the identification of re-vaporized species and their kinetics.

Preliminary results of the study have been published before [31], [32] and were focused mainly on the re-vaporization of Csl aerosol deposits in pure atmosphere (air or steam). This paper expands on the previous results and presents the re-vaporization of different types of CsI deposits in a mixed air/steam carrier gas as well as investigates the release kinetics for gaseous molecular iodine. Special attention was brought to the substrate nature, and its preparation in order to obtain a surface state 
as similar as possible of RCS inner parts after several hours of oxidation in steam conditions [32] [33] at high temperature. The surfaces before and after deposit re-vaporization process were carefully determined by combining X-Ray Photoelectron Spectroscopy (XPS) and Time-of-Flight Secondary lon Mass Spectrometry (ToF-SIMS). The release rate was monitored by thermogravimetric analysis (TGA) and the nature of released vapours was determined. Also, the release kinetics for molecular iodine has been studied by a novel spectroscopic technique, Incoherent Broadband Cavity Enhanced Absorption Spectroscopy (IBB-CEAS) [34].

Hereafter the article is composed of an experimental section which describes the equipment used and the analytical techniques employed. The following section presents the experimental results concerning the re-vaporization Csl deposits. Finally, a theoretical modelling of the experiments is done, in order to improve the understanding of the reaction mechanisms.

\section{Materials and methods}

The experimental study is based on a multistep approach including:

- Substrate pre-oxidation;

- Csl deposits generation;

- Csl deposits thermal treatment.

After each step the samples are characterized in order to establish the surface state of the substrate (XPS, ToF-SIMS), deposit quantity (ICP-MS), mass balance for caesium and iodine after revaporization (ICP-MS, TGA, UV-Visible spectroscopy).

\subsection{Substrate pre-oxidation}

304L stainless steel coupons $(8 \times 15 \times 2 \mathrm{~mm})$, whose composition is presented in Table 1 , underwent a thermal treatment in a controlled atmosphere in a flow reactor to reproduce as close as possible the surface state of the RCS inner part in SA conditions. The thermal treatment consisted in exposing the coupons to a flow of argon/steam (\% vol. 50/50) at $750^{\circ} \mathrm{C}$ during $24 \mathrm{~h}$. The heating rate was $5{ }^{\circ} \mathrm{C} / \mathrm{min}$ and steam was injected at $150{ }^{\circ} \mathrm{C}$. The total gas flow rate was fixed at $1 \mathrm{~L}_{\mathrm{n}} / \mathrm{min}^{1}$ at standard conditions. $316 \mathrm{~L}$ foils $(100 \times 500 \times 0.075 \mathrm{~mm}$, see composition in Table 1$)$ were pre-oxidized in the same thermal conditions and process gas composition, except that the total gas flow was $4 L_{n} / \mathrm{min}$ at standard conditions. In both case, the carrier gas flow was laminar and steam proportion in the flow $(50 \%)$ is large enough to allow equivalent oxidation conditions of the stainless steel surfaces.

Table 1. General composition (wt. \%) of the 304L and 316L stainless steels ([32])

\begin{tabular}{|l|l|l|l|l|l|l|l|l|}
\hline & $\mathrm{C}$ & $\mathrm{Cr}$ & $\mathrm{Fe}$ & $\mathrm{Mn}$ & $\mathrm{Mo}$ & $\mathrm{Ni}$ & $\mathrm{Si}$ & Other \\
\hline $304 \mathrm{~L}$ & 0.03 & $18.0-20.0$ & base & 2.0 & & $8.0-12.0$ & 1.0 & $\mathrm{P}, \mathrm{S}<0.045$ \\
\hline $316 \mathrm{~L}$ & 0.03 & $16.0-18.0$ & base & 2.0 & $2.0-3.0$ & $10.0-14.0$ & 0.75 & $\mathrm{P}, \mathrm{S}<0.025$ \\
\hline
\end{tabular}

\subsection{CsI deposits generation}

\footnotetext{
${ }^{1}$ The gas flow rates are given for the reference conditions: $273 \mathrm{~K}, 101325 \mathrm{~Pa}$ and are thus noted $\mathrm{L}_{\mathrm{n}} / \mathrm{min}$
} 
In this study three types of CsI deposits were considered: aerosols impaction at room temperature by Room temperature (RT) aerosol impaction, high-temperature vapour deposition/condensation and temperature aerosol deposition.

The Csl impacted aerosols were obtained following the procedure described by Obada et al. [33] which consists in nebulizing a concentrated Csl aqueous solution. The obtained wet aerosols are then dried in a strong argon flow $(10 \mathrm{~L} / \mathrm{min})$ and afterwards impacted on the pre-oxidized $304 \mathrm{~L}$ coupons placed in an exposition chamber (8 coupons per batch).

The high-temperature CsI deposits were generated using a high-temperature furnace. The thermal profile of the heated alumina tube is bell-shaped, with a $5 \mathrm{~cm}$ isotherm zone at the centre. An alumina crucible $(5 \mathrm{~cm}$ ) containing CsI powder (Acros Organics, 99.9\%) was placed inside a $1 \mathrm{~m}$ long alumina tube ( $30 \mathrm{~mm}$ inner diameter), inserted in the furnace. The crucible was placed in the isothermal zone. Downstream the alumina tube wall was lined by a $316 \mathrm{~L}$ pre-oxidized foil. The crucible was heated up to $750^{\circ} \mathrm{C}\left(5^{\circ} \mathrm{C} / \mathrm{min}\right.$ rate) and the temperature was maintained at $750^{\circ} \mathrm{C}$ for 6 hours. The carrier gas was a mixture of argon and steam (\% vol. 20/80) at total gas flow of 0.62 $\mathrm{L}_{\mathrm{n}} / \mathrm{min}$. The $316 \mathrm{~L}$ foil was placed in a strong thermal gradient as such vaporized CsI was transported by the carrier gas and was deposited along the pre-oxidized $316 \mathrm{~L}$ foil in a wide temperature range (from 750 to $150^{\circ} \mathrm{C}$ __ covering thus all deposition processes from a high temperature vapour deposition (above $620^{\circ} \mathrm{C}$ ), vapour condensation (between 620 and $400^{\circ} \mathrm{C}$ ) and aerosol deposition (below $440^{\circ} \mathrm{C}$ ). Downstream of the alumina tube was a series of two liquid scrubbers containing an alkaline solution ( $\mathrm{NaOH} 0.1 \mathrm{M}$ ) dedicated for steam condensation and trapping any non-deposited material. The line was terminated by an integral filter. After the test, the $316 \mathrm{~L}$ foil is recovered and divided into several sections ( $\sim 2-3 \mathrm{~cm}$ long and $1-2 \mathrm{~cm}$ large) based on a visual inspection of the deposit.

The deposited mass is determined after leaching one of the $304 \mathrm{~L}$ coupons (wet deposition) and a selection of small 316 samples, cut from the foil (high temperature deposit generation) in selected area, in alkaline media ( $\mathrm{NaOH} 0.1 \mathrm{M}$ ) for I and Cs recovery in solution followed by elemental I and $\mathrm{Cs}$ determination by Inductively Coupled Plasma - Mass Spectrometry (ICP MS -Varian 810 MS).

\section{CsI deposits thermal treatment}

The re-vaporization of CsI deposits from pre-oxidized stainless steel surfaces were carried out in a thermogravimetric analysis (TGA) device as described by Obada et al. [31]. Given the TGA furnace geometrical constraints (inner diameter of less than $1 \mathrm{~cm}$ ), only the $304 \mathrm{~L}$ coupons could be thermally treated in this device. The thermal treatment consisted in heating the samples up to $750^{\circ} \mathrm{C}$ (except for some tests, where samples were heated up to $970^{\circ} \mathrm{C}$ or $550^{\circ} \mathrm{C}$ only) at a rate of $5^{\circ} \mathrm{C} / \mathrm{min}$ and hold for 1 hour, before cooling down by natural convection. The rate of the heating ramp is a compromise between chemical equilibrium conditions and test duration (2-3 hours) [35]. During the thermal cycle, the sample is swept by a low carrier gas flow either composed of synthetic air ( $30 \mathrm{~mL} / \mathrm{min}$ ) or air/argon/steam mixtures (air/steam mixture featuring a total flow rate of $30 \mathrm{~mL} / \mathrm{min}$; argon flow rate set at $70 \mathrm{~mL} / \mathrm{min}$ ). Air/steam mixtures were injected at temperature above $150^{\circ} \mathrm{C}$ and switched off during the cooling phase (below $400^{\circ} \mathrm{C}$ ).

The main outcome of the TGA tests is the onset temperature of the mass loss linked to the start of the re-vaporization process. The overall mass change (loss) cannot be considered as a measure of CsI 
re-vaporization as the oxidation of the substrate during the thermal treatment may counterbalance the mass loss linked to re-vaporization. On the more, the inner alumina liner of the TGA device presents an important reduction in diameter (from $1 \mathrm{~cm}$ to $0.4 \mathrm{~cm}$ (Obada [2017]) just downstream of the sample, probably inducing at its vicinity some perturbation in the fluid flow which may enhance deposit retention on the sample.

To complement the results obtained by TGA, the RIGolo (Re-vaporization of lodine in Gaseous form and "piccolo"="small" in Italian) experimental device has been developed with a double purpose:

- Establish the nature and quantity of released iodine-containing species;

- Determine the release kinetics for gaseous molecular iodine.

It is an open flow reactor (Figure 1) composed of a tubular furnace (WATLOW ceramic heater CF$964255,15 \mathrm{~cm}$ ) in which an alumina tube ( $45 \mathrm{~cm}$ long, $20 \mathrm{~mm}$ inner diameter) is inserted. The sample is placed at the centre of the furnace and the carrier gas is fed up at the inlet of the test line. The vaporized vapour and/or generated aerosols from the heated sample are transported by the carrier gas to the line outlet. Based on the type of information searched in the experiment, the downstream part of the RIGolo device has two configurations: "integral measurement" for determining the nature and quantity of released iodine-containing species and "online measurement" for establishing the gaseous $I_{2}$ release kinetics.

The "integral measurement" configuration is described by Obada et al. [31] and consists in connecting the alumina tube outlet to a series of selective liquid scrubbers, containing a mix of toluene/acidic water. It has been shown that in these conditions molecular iodine will be selectively trapped in the organic phase, while inorganic iodine compounds (Csl, $\mathrm{HI}$ ) will be trapped in the aqueous phase [36] [37]. Since the detection limit of $I_{2}$ in toluene by UV-Visible spectroscopy is between $2 \times 10^{-8}$ and $6 \times 10^{-7} \mathrm{~mol} / \mathrm{L}$ (for the absorption wavelengths of $309 \mathrm{~nm}$ and $496 \mathrm{~nm}$ respectively), it is necessary to accumulate $I_{2}$ over a long period of time $(2 \mathrm{~h})$, hence the experiment was called "integral".

The "online measurement" configuration consists in connecting the alumina tube outlet to an Incoherent Broadband Cavity Enhanced Absorption Spectroscopy (IBB-CEAS) device dedicated to monitor online the gaseous molecular iodine concentration, transported up to the optical cell, by absorption spectroscopy in the 510-570 $\mathrm{nm}$ range [38] [34]. In this case the re-vaporization products (gaseous species, aerosols) are diluted in an argon flow before being injected in the optical cell. The technique has a low detection limit ( $1 \mathrm{ppb}$ volumic in the gas phase) and a good temporal resolution (10 s), which makes possible a kinetic study in our experimental conditions (1-2 mg of iodine revaporized for $\approx 1 \mathrm{~h}$ in a $200 \mathrm{~mL}_{\mathrm{n}} / \mathrm{min}$ gas flow). 


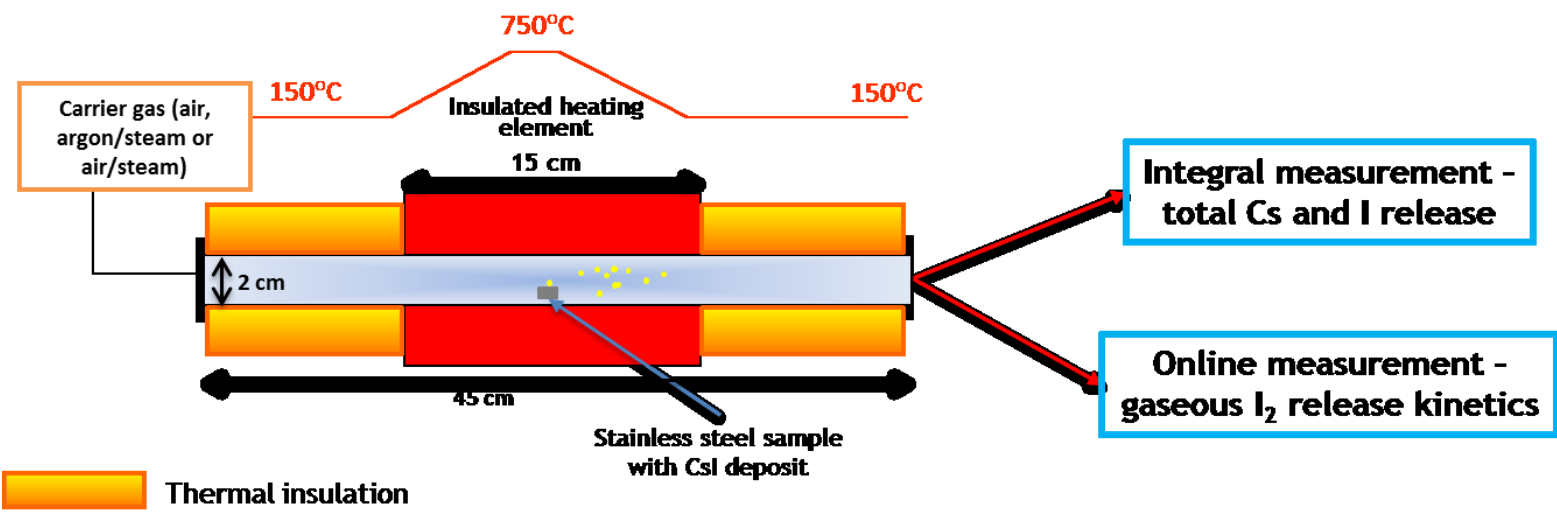

Figure 1. General design of the RIGolo experimental device

The thermal treatment in the RIGolo device is similar to the one applied in the TGA device: heating up to $750^{\circ} \mathrm{C}$ (rate $5^{\circ} \mathrm{C} / \mathrm{min}$ ) and hold for 1 hour, before cooling by natural convection. The carrier gas during the tests was either air $(53 \mathrm{~mL} / \mathrm{min})$ or a mixture of air/steam $(200 \mathrm{~mL} / \mathrm{min})$ of variable composition. The gas flow rates have been adjusted to the new alumina tube inner diameter, in order to have the same gas velocity above the sample as in the TGA tests.

\subsection{Post-test analysis}

\subsubsection{Elemental mass balance determination}

After each test, the entire facility, including the stainless steel and gold coupons, was leached in alkaline media for iodine and caesium deposits recovery and elemental determination. As in [31], the solutions were analysed by ICP-MS for elemental quantification with an uncertainty of + /- $8 \%$ (at 95 $\%$ confidence level). The organic phase of the liquid scrubbers has been also recovered and analy sed by UV-Visible spectroscopy for quantification of $\mathrm{I}_{2}$ in toluene, which was performed with an Agilent Cary 8454 spectrometer at $309 \mathrm{~nm}$ and $496 \mathrm{~nm}$ with an uncertainty of $+/-6 \%$ (at $95 \%$ confidence level).

\subsubsection{Surface Characterization Techniques}

The sample surface was characterized by combination of X-ray Photoelectron Spectroscopy (XPS) and Time-of-Flight Secondary lon Mass Spectrometry (ToF-SIMS). XPS provides chemical composition of less than $10 \mathrm{~nm}$ depth scale of the surface while the ToF-SIMS was used in depth profiling mode to reach composition up to several micrometres in depth. The morphology of the surface before and after re-vaporization was investigated by Scanning Electron Microscopy (SEM).

XPS measurements were carried out on a Kratos AXIS Ultra ${ }^{\text {DLD }}$ spectrometer equipped with a monochromatic Al Ka source $(1486.6 \mathrm{eV})$. Calibration was done by using the $\mathrm{C} 1 \mathrm{~s}$ component of adventitious at $\mathrm{BE}$ (binding energy) $=285.0 \mathrm{eV}$. Binding energy value uncertainty is $+/-0.1 \mathrm{eV}$ and uncertainty on quantitative elemental analysis is $+/-10 \%$.

ToF-SIMS analyses were carried out using a ToF-SIMS 5 instrument (ION-TOF GmbH). Pulsed $\mathrm{Bi}^{+}$ primary ions have been used for analysis $(25 \mathrm{keV}, \approx 1 \mathrm{pA})$ and $\mathrm{O}_{2}{ }^{+}$for sputtering $(2 \mathrm{keV}, \approx 500 \mathrm{nA})$. Given the sputter parameters, estimated sputter speed is $1.6 \mathrm{~nm} / \mathrm{s}$. Mass spectra were recorded in positive (for each sample) and negative for one sample polarity from an analysis area of $100 \mu \mathrm{m} x$ 
$100 \mu \mathrm{m}$ centred into a $300 \mu \mathrm{m} \times 300 \mu \mathrm{m}$ sputtered area. Charging effects, due to analysis and erosion ion beam, were compensated using low energy electrons $(20 \mathrm{eV})$.

Scanning Electron Microscopy (SEM) images were obtained using a LEO-435 VP microscope. A $20 \mathrm{kV}$ accelerating voltage was used giving an interaction depth above $2.5 \mu \mathrm{m}^{3}$.

\subsubsection{IBB-CEAS signal interpretation and presentation}

The IBB-CEAS configuration and characteristics are extensively discussed in [38] and [34]. It is based on the $I_{2}$ fine resolved spectrum in the $510-570 \mathrm{~nm}$ spectral range owing to the numerous rovibronic transitions in the $I_{2} B \leftarrow X$ electronic absorption spectrum [38]. The light source is a LED emitting in the 480-580 $\mathrm{nm}$ and the detector is a CCD camera (Andor iDus).

As explained by Bahrini et al. [38] and Johansson et al. [34], the $I_{2}$ spectra registered by the CCD detector require mathematical processing in order to separate the spectral contribution of gaseous molecular iodine from the continuous component of the spectra. Moreover, for practical reasons [38], a calibrated source of $I_{2}$ is analysed by the IBB-CEAS at the beginning of each experiment. lodine concentration in the sample is then displayed as the adimensional $\mathrm{N}_{\text {rel }}$ value which is the ratio of $\mathrm{I}_{2}$ sample concentration to the calibration source concentration. Absolute concentration in the samples requires to be adjusted for the sampling, calibration and dilution flow rates. In our case, as the main objective is to determine the release kinetic, it was decided to stay with relative concentration. For comparison purpose, the kinetic curves were rescaled based on the overall fractional release of moleculariodine, whenever possible (data from integral RIGolo experiments). Hereafter the figures displaying $I_{2}$ release kinetics present the rescaled $N_{\text {rel }}$ evolution as a function of time and temperature.

\subsubsection{DFT Calculations}

All DFT (density functional theory) calculations were carried out with VASP (Vienna Ab initio Simulation Package [39] [40] [41]. Plane waves are used to describe the wave functions and the PAW (Projector Augmented Wave) [42] method for electron-ion interactions. The energy is calculated using GGA as parametrized by Perdew et al., [43] and with a Methfessel-Paxton[44] smearing parameter sigma set to $0.1 \mathrm{eV}$. The Kohn-Sham equations are solved self-consistently until the energy difference between two successive steps is lower than $10^{-5} \mathrm{eV}$. The atomic positions were optimized without symmetry constraints until the forces being less than $0.03 \mathrm{eV} / \AA \AA \AA$. The electron configurations [Xe] 6s1, [Kr] 4d10 5s2 5p5, [He] 2s2 2p4 and 1s1 were used for caesium, iodine, oxygen and hydrogen respectively. The cut of energy was set to $450 \mathrm{eV}$ and $3 \times 3 \times 1$ or larger K-point meshes [45] have been used for all the surface calculations (distance between $\mathrm{K}$ point smaller than $0.035 \AA^{-1}$ ). Van der Waals interactions are included in the calculation through the TSHI formalism [46] that take into account the charges on the atoms.

The adsorption energy $\left(E_{a d s}\right)$ is defined as the opposite of the adsorption reaction energy. A positive adsorption energy is associated to an exothermic adsorption.

$$
A_{(g)}+\text { Surface }=A \text {-Surface } \quad E_{a d s}=E\left(A_{(g)}\right)+E(\text { Surface })-E(A-\text { Surface }) .
$$

\section{Experimental matrix}


The first tests concerning the re-vaporization of Csl aerosols (Room temperature aerosol impaction) from pre-oxidized 304L or 316L substrate in presence of argon/steam have shown an integral release of Cs and I [31]. As such these test conditions will serve as reference. The goal of this research was to assess gaseous iodine release during re-vaporization of Csl deposits, through small-scale analytical tests.

Stainless steels of different grades (304L or 316L) were used to represent the inner surface of the RCS in general. The coupons were pretreated (pre-oxidation at $750^{\circ} \mathrm{C}$ in steam conditions) so as to feature a surface state representative of the RCS in case of a SA. As reported in [32], the structure of surface oxide is similar for both stainless steels grades and has no influence on the CsI revaporization behaviour. In the case of $316 \mathrm{~L}$ foils, oxide structure is slightly different, presenting an outer Fe-rich layer (as opposed to a Mn-rich layer) and an inner Cr-rich layer. Nevertheless, taking into account the thickness of the deposit (estimated to be in the range of 2-7 $\mu \mathrm{m}$ for $1-3 \mathrm{mg} / \mathrm{cm}^{2}$ for deposited CsI), we expected a low contribution of deposit/surface interaction on re-vaporized species. Indeed, for such thick deposits, the fraction of Csl in contact with the substrate surface is low.

Except for one test, the same thermal cycle was applied: heating at $5^{\circ} \mathrm{C} / \mathrm{min}$ up to $750^{\circ} \mathrm{C}$. This final temperature is high enough to be able to catch every rel ease events concerning CsI re-vaporization and remains within the expected temperature range which could prevail in the RCS during a late SA phase.

The study was focused on the two main following parameters (see table 2):

- The CsI deposition process, to be able to reproduce the different deposition zone sin the RCS: RT temperature aerosol impaction (simulating CsI deposition in the cold leg of the RCS), high temperature vapour deposition (above $620^{\circ} \mathrm{C}$, simulating a deposition in the hot leg of the RCS and SG inlet), vapour condensation $\left(620-400^{\circ} \mathrm{C}\right.$, simulating SG deposition) and temperature aerosol deposition (around $400^{\circ} \mathrm{C}$, SG deposition).

- The atmosphere composition featuring either air, air/steam mixtures and argon/steam. Air and steam atmospheres are not representative of SA scenario but may help in understanding the Csl re-vaporization behaviour and gaseous iodine production. Realistic atmospheres are mixture of air/steam with a low air content. Re-vaporization of Csl aerosols (RT aerosol impaction) on $304 \mathrm{~L}$ coupons featured the largest atmosphere compositions (5 different compositions as reported in table 2, from pure air contents to argon/steam). Tests were performed in both TGA and RIGolo devices. Based on the results of this test series, the number of tested atmospheres has been reduced for the Csl vapour deposition and vapour condensation: one test in steam, one in air and one in a 20/80 air/steam atmosphere. Finally, for the deposit obtained by temperature aerosol deposition $\left(400{ }^{\circ} \mathrm{C}\right)$, only the pure air and steam atmospheres have been retained for the re-vaporization tests, to check for consistency with Csl aerosol impaction at room temperature. The tests have been performed in the RIGolo device only, as the 316L foil samples were not suited for the TGA device (see table2).

Two complementary tests were performed: 
On test with an inert substrate to assess the contribution of deposit/surface interaction in terms of nature of re-vaporized species (especially for iodine). Csl aerosols were deposited on gold coupons by the room temperature aerosol impaction process. Tests conditions featured air atmosphere and a thermal cycle $\left(5^{\circ} \mathrm{C} / \mathrm{min}\right.$ up to $\left.750^{\circ} \mathrm{C}\right)$ similar to conditions 1 . Tests were performed in both devices (TGA and RIGolo) to allow a complete comparison with condition 1, table 2.

One test with a lower final test temperature $\left(550^{\circ} \mathrm{C}\right)$, dedicated to the observation of iodine revaporization kinetics at low temperature. This test was conducted with initial CsI RT aerosol deposits on a stainless steel coupon ad a mixed steam/air atmosphere was applied (instead of pure air) to be more representative of a reactor case. This test was performed in the $\mathrm{RIGolo} \mathrm{device} \mathrm{in} \mathrm{the} \mathrm{I}_{2}$ on-line monitoring configuration. The sample was initially heated up to $420^{\circ} \mathrm{C}$ in argon (rate $5^{\circ} \mathrm{C} / \mathrm{min}$ ), then the carrier gas was switched for a mixture of air/steam (\% vol. 50/50). After that the sample was heated up to $550^{\circ} \mathrm{C}$ (rate $5^{\circ} \mathrm{C} / \mathrm{min}$ ) and held for $4 \mathrm{~h}$ before cooling by natural convection. The upper limit for temperature was chosen based on the results of Bottomley et al. [11], where it has been observed that Cs re-vaporization is much slower and less significant after $750-800^{\circ} \mathrm{C}$.

Table 2. Csl re-vaporization - Experimental matrix for test performed with thermal cycle up to $750^{\circ} \mathrm{C}$ at $5^{\circ} \mathrm{C} / \mathrm{min}$.

\begin{tabular}{|c|c|c|c|c|c|c|}
\hline \multirow{2}{*}{ Substrate } & \multirow{2}{*}{ Deposition process } & \multirow{2}{*}{$\begin{array}{l}\text { Re-vaporization } \\
\text { carrier gas (\% vol) }\end{array}$} & \multicolumn{3}{|c|}{ Experiment type (repeat) } & \multirow{2}{*}{ Condition $\mathrm{n}^{\circ}$} \\
\hline & & & |ntegral $^{1}$ & Kinetic $^{2}$ & $\mathrm{TGA}^{3}$ & \\
\hline \multirow{5}{*}{ 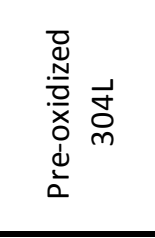 } & \multirow{5}{*}{$\begin{array}{l}\text { Aerosols impaction } \\
\text { at room temperature }\end{array}$} & Air $(100 \%)$ & $x[31](3)$ & $x$ & $x[31]$ & 1 \\
\hline & & Air/steam $(50 / 50)$ & $\mathrm{x}$ & $\mathrm{x}$ & & 2 \\
\hline & & Air/steam $(20 / 80)$ & $X(2)$ & $\mathrm{x}$ & $\mathrm{x}$ & 3 \\
\hline & & Air/steam (3/97) & $x$ & $x$ & $x$ & 4 \\
\hline & & Argon/steam (50/50) & $x[29]$ & & $x[29]$ & 5 \\
\hline \multirow{8}{*}{ 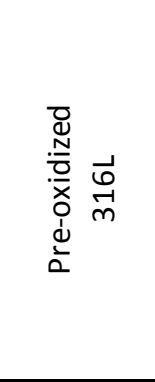 } & \multirow{3}{*}{$\begin{array}{c}\text { High-temperature } \\
\text { vapour deposition } \\
\left(720-620^{\circ} \mathrm{C}\right)\end{array}$} & Air (100\%) & $\mathrm{x}$ & $x$ & & 6 \\
\hline & & Air/steam (20/80) & $\mathrm{x}$ & & & 7 \\
\hline & & Argon/steam (50/50) & $x$ & & & 8 \\
\hline & \multirow{3}{*}{$\begin{array}{c}\text { Vapour } \\
\text { condensation }(620- \\
\left.440^{\circ} \mathrm{C}\right) \\
\end{array}$} & Air (100\%) & $X(2)$ & $\mathrm{x}$ & & 9 \\
\hline & & Air/steam (20/80) & $\mathrm{x}$ & $\mathrm{x}$ & & 10 \\
\hline & & Argon/steam (50/50) & $x$ & & & 11 \\
\hline & \multirow{2}{*}{$\begin{array}{l}\text { Aerosols deposits }(< \\
\left.400^{\circ} \mathrm{C}\right)\end{array}$} & Air (100\%) & $x$ & & & 12 \\
\hline & & Argon/steam (50/50) & $x$ & & & 13 \\
\hline Gold $(A u)$ & RT aerosol impaction & Air (100\%) & $x$ & $x$ & $x$ & 14 \\
\hline
\end{tabular}

\section{Results}

\subsection{Deposit characterization}

After the pre-oxidation of $304 \mathrm{~L}$ and $316 \mathrm{~L}$ stainless steel coupons and foil, CsI is deposited as described in section 2.2. Afterwards the size and the morphology of the deposits are characterized by SEM and the amount of deposited CSI is determined by ICP-MS after lixiviation.

The CsI aerosols deposits obtained by impaction at room temperature have been described by Obada et al. [33]. SEM analysis has revealed the presence of particles with irregular shapes and particle agglomerates with sizes from 5 to $20 \mu \mathrm{m}$. After several weeks, the particles also appear to hydrate, given the hygroscopic nature of CSI [47]. ICP-MS analysis has revealed similar CsI quantity among all 
the $304 \mathrm{~L}$ coupons of the same batch, with values ranging from 0.8 to $4.2 \mathrm{mg} / \mathrm{cm}^{2}$ of Csl from one experiment to another.

The Cs and I deposits obtained at high temperature, on the other hand, exhibit different size s and morphologies based on the deposition temperature. For instance, in the $720-620^{\circ} \mathrm{C}$ temperature range, SEM analysis has revealed an amorphous deposit, homogeneously spread across the entire surface of the 316 foil (Figure 2a) - corresponding to the deposition of liquid droplets. The average amount of caesium and iodine per surface unit in this temperature range is about $2.9 \mathrm{mg} / \mathrm{cm}^{2}$, as determined by ICP-MS analysis. Also, the Cs/I mass ratio of 0.94 is consistent with to the theoretical value (1.05) taking into account uncertainties measurement, which strongly suggests that caesium and iodine were deposited as CsI. In the $620-440^{\circ} \mathrm{C}$ temperature range, the deposit is composed of polyhedrons that range between 10 and $30 \mu \mathrm{m}$ in size, as well as acicular particles with lateral dendrites that reach several hundred microns in size (Figure $2 \mathrm{~b}$ ). The deposit in this temperature range is the most important in terms of quantity, up to $8.3 \mathrm{mg} / \mathrm{cm}^{2}$, and the $\mathrm{Cs} / \mathrm{I}$ mass ratio $(0.96)$ suggests that the chemical species is Csl. Below $440^{\circ} \mathrm{C}$, the deposit consists of spherical particles that reach up to $4 \mu \mathrm{m}$ in diameter (not presented here). The amount of deposit decreases progressively from $4.3 \mathrm{mg} / \mathrm{cm}^{2}$ at $440^{\circ} \mathrm{C}$ to $0.7 \mathrm{mg} / \mathrm{cm}^{2}$ at $150^{\circ} \mathrm{C}$. Given the Cs/I mass ratio (0.89-0.99), it is highly likely that the deposit is composed of Csl.
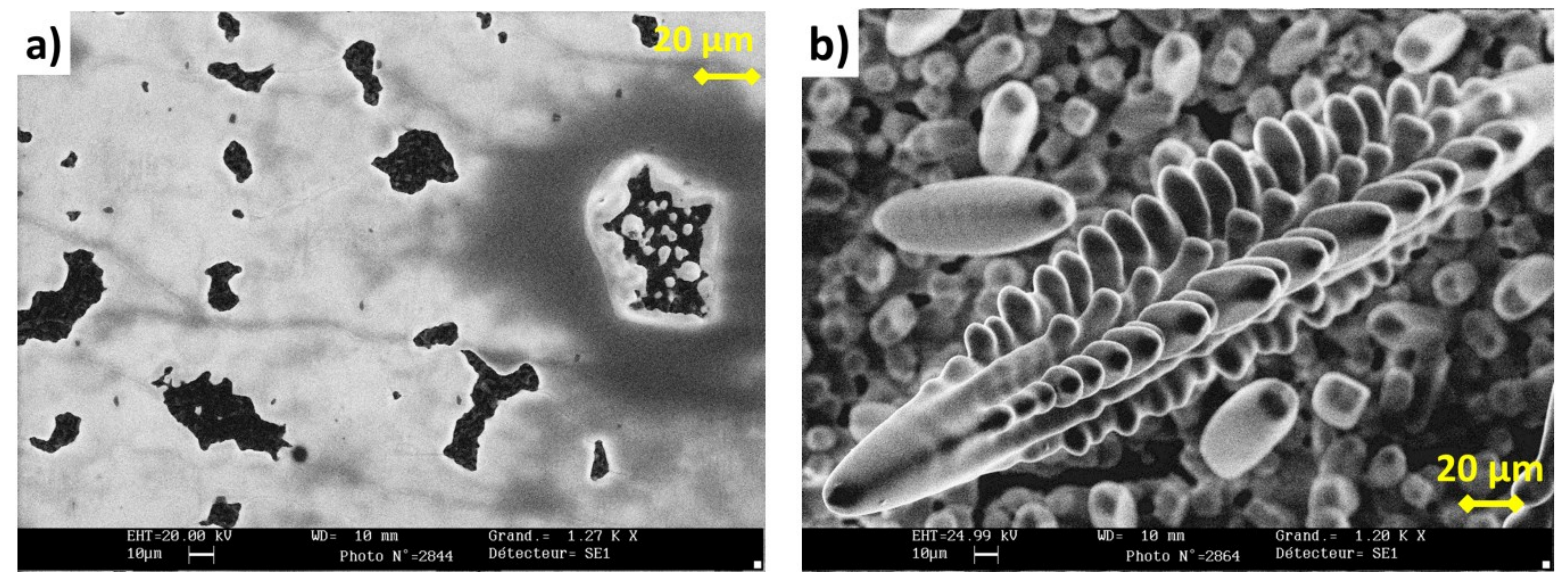

Figure 2. SEM images of high-temperature CSI deposit on pre-oxidized $316 \mathrm{~L}$ foil: a) between $720-620^{\circ} \mathrm{C}$ and b) between $620-440^{\circ} \mathrm{C}$.

\subsection{Re-vaporization: identification of released and residual species and release kinetics}

In this chapter are presented the results of RIGolo and TGA tests in different conditions (Table 2) as well as the results of the kinetics tests. Since the goal is to investigate the separate effect of different parameters, the results are presented following the listed parameters: carrier gas composition, deposition process, substrate nature (stainless steel vs gold) and finally low temperature revaporization. Here the main trends will be discussed depending on the test parameters. Variability in test results may occur for equivalent test conditions (and for repeats) due to inhomogenities of CsI deposits.

\subsubsection{Influence of carrier gas composition: air vs. mixed air/steam (conditions 1 to 5 )}

As previously reported [31] [33], the carrier gas composition during the re-vaporization phase is one of the key parameters regarding the nature of re-vaporized and residual species. As such, in an 
argon/steam carrier gas, caesium and iodine are released integrally from the surface of stainless steel coupons (condition 5). The absence of gaseous iodine species at the line outlet and Cs/I ratios measured downstream of the steel coupon close to $\sim 1.1$ (main line data), suggest a re-vaporization as CsI only [31].

With the addition of air in the carrier gas (in increasing amounts following conditions 4, 3, 2 up to pure air, condition 1), we can observe that the overall fraction of released molecular iodine (RIGolo test in integral configuration) is roughly the same ( $\sim 23-33 \%$ of total iodine) as soon as air is present in the gas phase, except for pure air conditions featuring much higher gaseous iodine releases (up $75 \%$ of total iodine amount). Indeed, oxygen is always present in sufficient amount to react with iodine taking into account the oxygen flow (from $\sim 0.02$ up to $0.7 \mathrm{mg} / \mathrm{s}$ ), the test duration ( 2 hours of heating and one hour at $750^{\circ} \mathrm{C}$ ) and the initial iodine mass (1-2 mg) - so that the role of oxygen is expected to be the same in all the cases as soon as it is present (see section 5 for theoretical part). In pure air, TGA tests have shown that the release starts at $420^{\circ} \mathrm{C}$ on average, releases seems to be delayed as soon as steam is present with onset temperatures in the $450-470^{\circ} \mathrm{C}$ range. These observations (lower gaseous iodine releases and higher re-vaporization onset temperature) in air/steam conditions compared to pure air condition may be owed to possible limiting effects of steam which are not yet understood.

Concerning the residue (RIGolo tests in integral configuration), the ICP-MS analysis of the leaching solutions of the stainless steel coupons has consistently revealed the absence of iodine, which implies its total re-vaporization, and the presence of a residual amount of caesium. In pure air (Table 3 , condition $n^{\circ} 1$ ), Cs retention amounts up to $10 \%$ of the total measured amount at the end of the test. The ICP-MS analysis of the alumina tube leachate shows a Cs/I mass ratio in between $\approx 5-11$. This feature indicates that beside CsI, Cs is mainly deposited in other chemical forms - expected to be $\mathrm{CsO}$ as this species is the most stable from a thermodynamic point of view in the absence of steam. In air/steam, Cs retention on the coupon represents up to $9 \%$ of total Cs collected mass (Table 3 , conditions $n^{\circ} 2 \& 3$ ). The integral experiment in conditions $n^{\circ} 4$, which featured the smallest ratio of air to steam (\% vol. $3 / 97$ ), has resulted in a residual amount of Cs of only $1.5 \%$. The Cs/I mass ratio in the alumina tube does not vary a lot when considering all the mixed air steam conditions (1.4-1.6). This value is still above the Cs/I mass ratio of Csl (1.05) and support the hypothesis that beside Csl, other Cs compounds may have deposited in the main line (though in a lesser extent compared to pure air condition). In presence of steam, the other expected Cs compound is $\mathrm{CsOH}$.

A detailed surface characterization by XPS and ToF-SIMS of 304L samples after re-vaporization in air or argon/steam has been discussed by Obada et al. [33]. The same process has been applied to the 304L samples obtained after re-vaporization in air/steam atmosphere and the results show evidence of the formation of mixed $\mathrm{Cs}-\mathrm{Cr}$ oxides, specifically $\mathrm{Cs}_{2} \mathrm{CrO}_{4}$ and $\mathrm{Cs}_{2} \mathrm{Cr}_{2} \mathrm{O}_{7}$. This observation is supported by XPS analysis which revealed the presence of two chemical forms of chromium: $\mathrm{Cr}$ (III) and $\mathrm{Cr}(\mathrm{VI})$ oxides. Also, ToF-SIMS analysis has revealed the presence of secondary ion clusters $\mathrm{Cs}_{2} \mathrm{CrO}_{3}{ }^{+}$and $\mathrm{Cs}_{2} \mathrm{Cr}_{2} \mathrm{O}_{9} \mathrm{H}^{+}$, which is a strong indication that the said oxides have been formed during the re-vaporization process. These results demonstrate that the nature of the support affect the behaviour of residual $\mathrm{Cs}+$ but not that the same support participate to the iodine oxidation but that in oxidizing condition, the chromium of the support can react with the air[48]. 
This test series (conditions 1 to 5) was complemented by RIGolo tests performed with the on -line configuration in order to monitor $\mathrm{I}_{2 \mathrm{~g}}$ release during the thermal treatment. Based on TGA tests results ( no release event below $400^{\circ} \mathrm{C}$ ), the $\mathrm{I}_{2}$ release kinetics was monitored from $\sim 330^{\circ} \mathrm{C}$ on.

A first test has been performed in an argon/steam atmosphere (condition 5), serving as reference (Figure 3, red curve). There is no signal increase up to $640^{\circ} \mathrm{C}$, indicating the lack of gaseous $\mathrm{I}_{2}$. The weak signal detected in the $640-680^{\circ} \mathrm{C}$ temperature range and interpreted as $N_{\text {rel }} \neq 0$ is nevertheless not representative of any $I_{2}$ release kinetics. Indeed, the raw spectra in this temperature range lack the fine structure of the $\mathrm{I}_{2}$ spectrum [38] [34] and thus the signal is attributed to the light extinction due to the presence of aerosols (probably Csl) transported up to the optical cell. This online measurement experiment with a sensitive technique confirmed the absence of gaseous molecular iodine released in steam conditions.

In pure air (Table 2, condition 1 ), $I_{2}$ release starts at approx. $440^{\circ} \mathrm{C}$, which is coherent with the TGA tests, and occurs in two steps (Figure 3 , blue curve):

1) Between $\approx 440-550^{\circ} \mathrm{C}$ a first slow and low release is observed ;

2) Above $550^{\circ} \mathrm{C}$ the majority of iodine is rapidly released (exponentially). Reproducibility tests have been performed in these conditions and the results were similar.

Further on, the re-vaporization tests in air/steam atmosphere (Table 2, conditions 2, 3 and 4) showed that $I_{2}$ release is initiated at a higher temperature, $\approx 480-500^{\circ} \mathrm{C}$ (Figure 4 ), compared to air revaporization, which is coherent to the TGA results of similar tests. While the release of $I_{2}$ in two steps is still noticeable for the \% vol. 50/50 (condition 2), it is less pronounced for the other two carrier gas compositions (conditions 3 and 4). It is also interesting to note that the release curves present "spikes" (above $\approx 520^{\circ} \mathrm{C}$ ), which resemble those in the case of argon/steam re-vaporization. This suggests the presence of a larger amount of aerosols, which in turn prevent a reliable measurement of $\mathrm{I}_{2}$. 
Table 3. Summary table of main experimental results.

\begin{tabular}{|c|c|c|c|c|c|c|c|c|}
\hline \multirow[b]{2}{*}{ Substrate } & \multirow[b]{2}{*}{ CsI deposit } & \multirow[b]{2}{*}{$\begin{array}{l}\text { Re-va porization } \\
\text { carriergas (\% vol) }\end{array}$} & \multicolumn{5}{|c|}{ Main results } & \multirow[b]{2}{*}{$\begin{array}{c}\text { Cond } \\
n^{\circ}\end{array}$} \\
\hline & & & $\begin{array}{c}\text { Temp. of } \\
\text { release } \\
\text { initiation }\left({ }^{\circ} \mathrm{C}\right)^{4} \\
\end{array}$ & $\mathrm{I}_{2}$ released $^{1,2}$ & Cs residual ${ }^{1,3}$ & I residual $^{1,3}$ & Cs/I line1 & \\
\hline \multirow{5}{*}{ 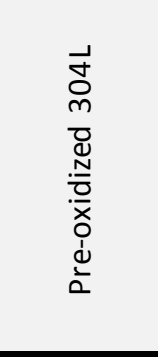 } & \multirow{5}{*}{$\begin{array}{c}\text { Aerosols } \\
\text { impaction at room } \\
\text { temperature }\end{array}$} & Air (100\%) & 420 & $50-75 \%$ & $<10 \%$ & $<1 \%$ & $5-11$ & 1 \\
\hline & & Air/steam $(50 / 50)$ & 460 & $26 \%$ & $6.5 \%$ & $<$ l.d. & 1.5 & 2 \\
\hline & & Air/steam (20/80) & 470 & $23-33 \%$ & $7-9 \%$ & $<$ l.d. & 1.6 & 3 \\
\hline & & Air/steam (3/97) & 450 & $26 \%$ & $2 \%$ & $<$ l.d. & 1.4 & 4 \\
\hline & & $\begin{array}{c}\text { Argon/steam } \\
(70 / 30)\end{array}$ & 480 & $0 \%$ & $3.4 \%$ & $<$ l.d. & 1.1 & $5[29]$ \\
\hline \multirow{8}{*}{ 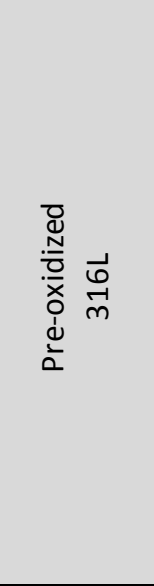 } & \multirow{3}{*}{$\begin{array}{l}\text { High-temperature } \\
\text { va pour deposition } \\
\quad\left(720-620^{\circ} \mathrm{C}\right)\end{array}$} & Air (100\%) & & $53 \%$ & $3.4 \%$ & $<$ l.d. & 10 & 6 \\
\hline & & Air/steam $(20 / 80)$ & & $13 \%$ & $9.7 \%$ & $8.6 \%$ & 1.6 & 7 \\
\hline & & $\begin{array}{c}\text { Argon/steam } \\
(70 / 30)\end{array}$ & & $0 \%$ & $1.9 \%$ & $<$ l.d. & 3.8 & 8 \\
\hline & \multirow{3}{*}{$\begin{array}{c}\text { Vapour } \\
\text { condensation } \\
\left(620-440^{\circ} \mathrm{C}\right)\end{array}$} & Air (100\%) & & $7-15 \%$ & $2.4-4.5 \%$ & $<1 \%$ & 1.3 & 9 \\
\hline & & Air/s team (20/80) & & $12 \%$ & $2.0 \%$ & $<1 \%$ & 1.1 & 10 \\
\hline & & $\begin{array}{c}\text { Argon/s team } \\
(70 / 30)\end{array}$ & & $0 \%$ & $0.5 \%$ & $0.6 \%$ & 3.1 & 11 \\
\hline & \multirow{2}{*}{$\begin{array}{l}\text { Aerosols deposits } \\
\qquad\left(<400^{\circ} \mathrm{C}\right)\end{array}$} & Air $(100 \%)$ & & $45 \%$ & $2.4 \%$ & $<$ l.d. & 12 & 12 \\
\hline & & $\begin{array}{c}\text { Argon/steam } \\
(70 / 30)\end{array}$ & & $0 \%$ & $2.9 \%$ & $1.0 \%$ & 1.2 & 13 \\
\hline Gold (Au) & $\begin{array}{c}\text { Aerosols } \\
\text { Impaction (RT) }\end{array}$ & Air (100\%) & & $28 \%$ & $0.4 \%$ & $<$ l.d. & 1.6 & 14 \\
\hline
\end{tabular}


${ }^{1}$ wt\% wrt the total collected Cs and I at the end of test

${ }^{3}$ As measured by ICP-MS
${ }^{2}$ As measured by UV-Visible spectroscopy

${ }^{4}$ As measured by TGA 6

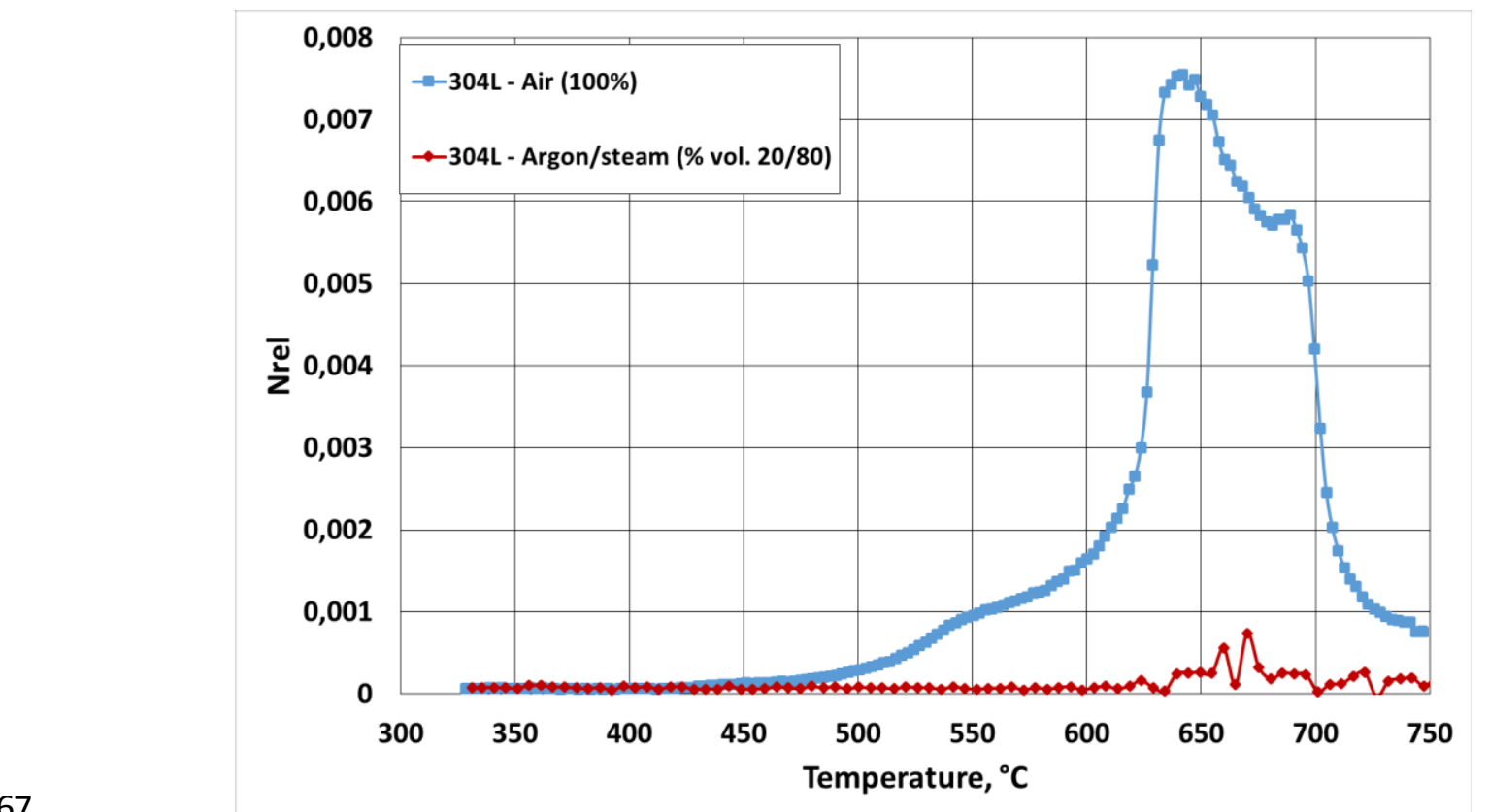

Figure 3. Release and transport kinetics of $\mathrm{I}_{2}$ during re-vaporization of Csl aerosols (RT aerosol impaction) with a heating rate of $5^{\circ} \mathrm{C} / \mathrm{min}$ up to $750^{\circ} \mathrm{C}$; blue curve : pure air with a flow rate of $53 \mathrm{~mL} / \mathrm{min}$ (condition 1) ; red curve : argon/steam (70/30) with flow rate of $200 \mathrm{~mL} / \mathrm{min}$ (condition 5).

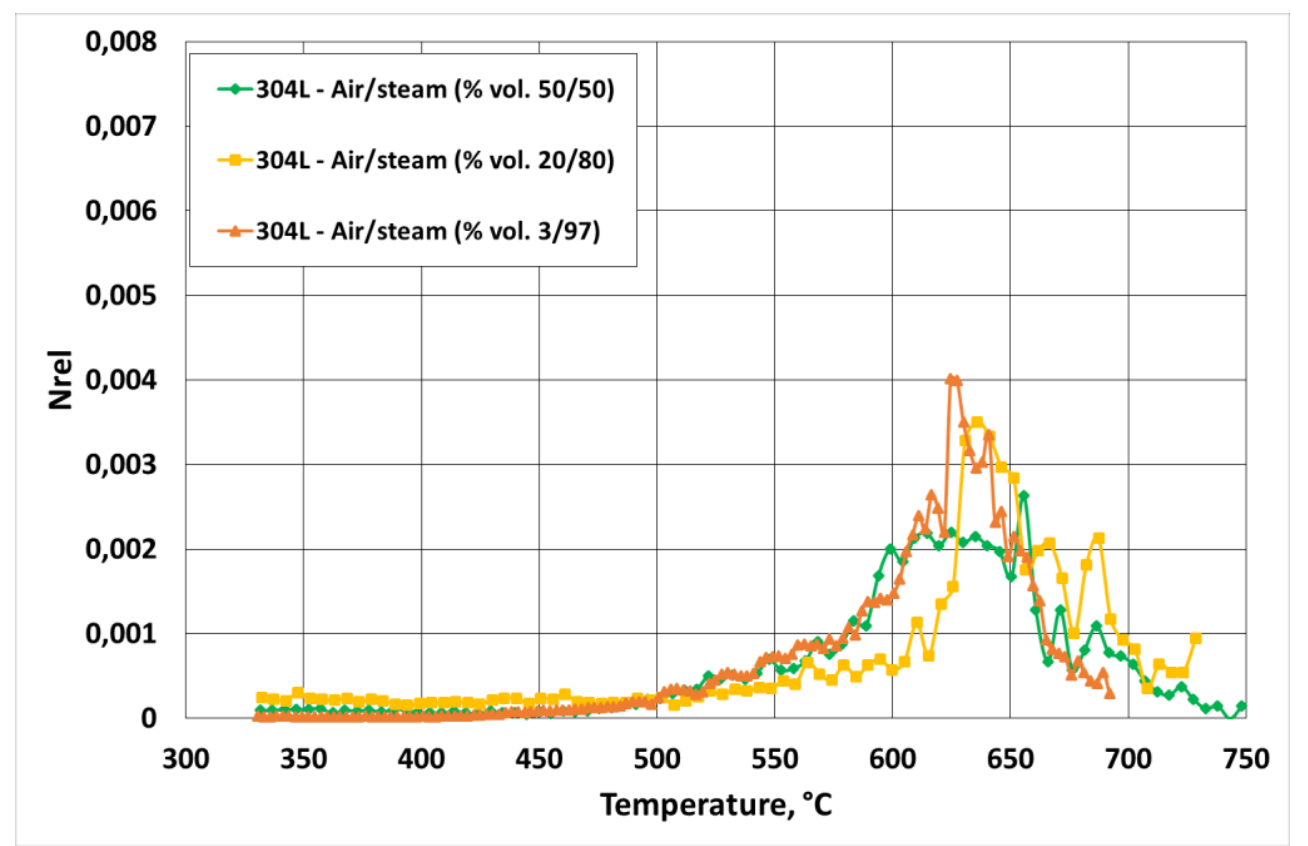

Figure 4. Release and transport kinetics of $\mathrm{I}_{2}$ during re-vaporization of $\mathrm{Csl}$ aerosols (RT aerosol impaction) with a heating rate of $5^{\circ} \mathrm{C} / \mathrm{min}$ up to $750^{\circ} \mathrm{C}$. green curve: air/steam \% vol. 50/50 (condition 2); yellow curve :, air/steam \% vol. 20/80 (condition 3); orange curve : air/steam \% vol. 3/97 (condition 4). Gas flow: $200 \mathrm{~mL} / \mathrm{min}$ for all conditions. 

impaction at room temperature

As a general rule, the re-vaporization of CsI deposits obtained by different routes follows the same trend if the same experimental conditions are applied.

Compared to RT aerosol impaction, Csl aerosols deposited in the $400-150^{\circ} \mathrm{C}$ temperature range present a similar re-vaporization behaviour with atmosphere composition (table 3, air and argon/steam conditions only): similar gaseous iodine releases and overall deposition trends were observed for the RIGolo integral tests. It is thus assumed that CsI re-vaporization behaviour is very close when considering deposited aerosols.

For the two other deposition routes (high temperature vapour deposition $720-620^{\circ} \mathrm{C}$ and vapour condensation $620-440^{\circ} \mathrm{C}$ ), re-vaporization in argon/steam (conditions 8 and 11) didn't lead to the release of $\mathrm{I}_{2}$; those results are comparable to the re-vaporization of $\mathrm{CsI}$ aerosols (conditions 5 and 12). Nevertheless, the $\mathrm{Cs} / \mathrm{I}$ mass ratio in the RIGolo line is much higher ( 3.8 and 3.1 for conditions 8 and 11 respectively)compared to condition 5(1.1). This observation indicates that besides Csl, other species can be involved during steam re-vaporization of such $\mathrm{Csl}$ deposits. $\mathrm{CsOH}$ is a possible candidate for the other Cs compounds, the iodine transported species could not be clearly identified.

Re-vaporization in air of the high-temperature deposits (condition $n^{\circ} 6$ ) and the aerosols deposits in has resulted in the release of $53 \%$ of iodine as $\mathrm{I}_{2}$. The ICP-MS analysis of the alumina tube leachate shows a Cs/I mass ratio 10. Both results are consistent with the re-vaporization behaviour of CsI aerosols as described in section 4.2.1. Only one mixed air/steam carrier gas composition (\% vol. $20 / 80)$ was tested with the high-temperature $\left(720-620^{\circ} \mathrm{C}\right.$, condition 7$)$ and vapour condensation $\left(620-440^{\circ} \mathrm{C}\right.$, condition 10$)$ deposits. The results show that $12-13 \%$ of iodine is released as $I_{2}$ and that the $\mathrm{Cs} / \mathrm{I} \approx 1.1-1.6$ in the alumina tube, which is again consistent with the results presented in section 4.2.1. However, there was a noticeable difference in the amount of released molecular io dine for condition 9. The re-vaporization in pure air of a Csl deposit obtained by vapour condensation $\left(620-440^{\circ} \mathrm{C}\right)$ resulted in the release of only $7-15 \%$ of $\mathrm{I}_{2}$, which is much lower when compared to the amount of released $\mathrm{I}_{2}$ in other experiments in the same re-vaporization conditions. The residual amount of $C s$ on the steel coupon is $2.4-4.5 \%$ and the $C s / I \approx 1.3$ in the alumina tube, suggesting the re-vaporization of $\mathrm{Cs}$ as several different species. The possible reasons, which may be linked to the organized crystalline structure of the deposit, are discussed further.

Surface characterizations by XPS and ToF-SIMS have been performed on the $316 \mathrm{~L}$ foils after CsI revaporization of high temperature deposits and condensed vapour (as displayed in figure 6). The presence of the mixed Cs-Cr-O compounds described above (see section 4.2.1) is confirmed (figure $6 \mathrm{~b}$, depth profiles in negative polarity), as soon as air is present in the carrier gas. Also, in both cases, the $\mathrm{Cs}$ depth profile indicates that $\mathrm{Cs}$ had migrated in the oxide layer during the thermal treatment or that the oxide layer may have growth up to the Csl deposit. Indeed the $\mathrm{Cs}_{2}{ }^{+}$and $\mathrm{Cs}_{2} \mathrm{I}^{+}$signals are very low at the surface and in the first oxide layer (composed of Fe and $\mathrm{Mn}$ ) and incre ase strongly in the second $\mathrm{Cr}$-Mn oxide layer (figure 6, depth profile in positive polarity). Migration of CsI inside the oxide layer may explain the significantly more important residual mass of Cs (9.7\%) and I (8.6\%) observed on the $316 \mathrm{~L}$ foil after re-vaporization of high-temperature vapour deposit in steam/air (table 3, condition 7). 

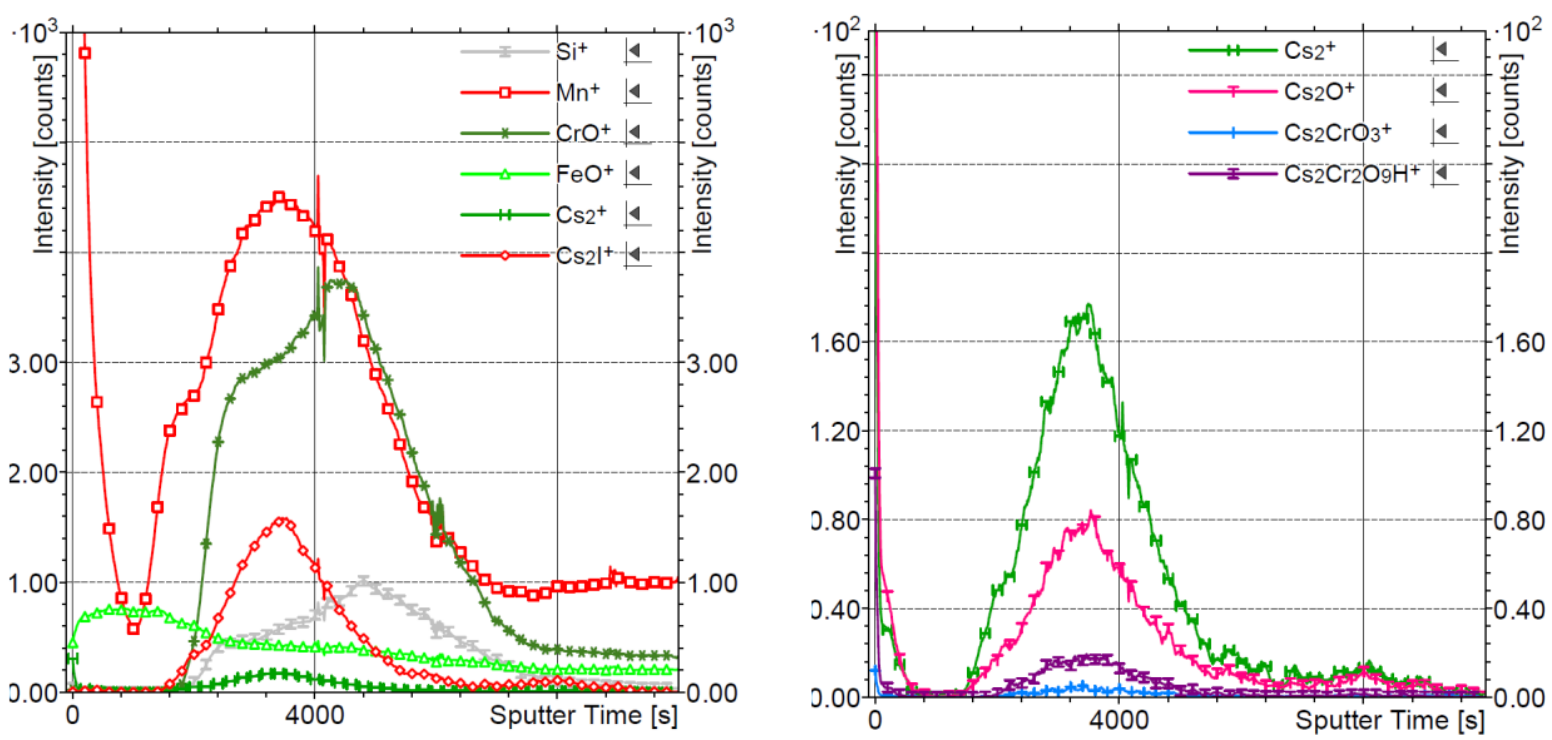

Figure 5. TOF-SIMS profile of CsI vapour condensation deposition 316L pre-oxidized foil and re-vaporized in air/steam atmosphere (condition 10, table 3 ). Secondary ions in positive polarity a) major fragments and b) minor fragments.

Based on the results of the integral tests, online measurement tests have been performed with $\mathrm{Csl}$ high-temperature $\left(720-620^{\circ} \mathrm{C}\right)$ and vapour condensation $\left(620-440^{\circ} \mathrm{C}\right)$ deposits with the same thermal cycle as for conditions 6 and 9 . The carrier gas was pure air. The $I_{2}$ release kinetics from CsI deposits obtained by vapour condensation (condition $n^{\circ} 9$ ) presents a similar pattern as from Csl deposits obtained by RT aerosol impaction (condition $n^{\circ} 1$ ) (Figure 6 ). The process occurred in two steps: 1 ) a slow and low release between $\approx 350-500^{\circ} \mathrm{C}$, and 2 ) a more rapid re-vaporization above $500^{\circ} \mathrm{C}$, which results in the total release of iodine from the surface of the pre-oxidized $316 \mathrm{~L}$ foil.

The kinetic study of $\mathrm{I}_{2}$ release in case of a high-temperature $\mathrm{Cs}$ l deposit $\left(720-620^{\circ} \mathrm{C}\right)$, on the contrary, has highlighted a new phenomenon. While the cumulated amount of released $\mathrm{I}_{2}$ is consistent with the release observed in condition 1 (RT aerosol impaction), the $I_{2}$ release and transport kinetics is slightly different (Figure 5 ). There is a two-step moleculariodine release between $\approx 400-550^{\circ} \mathrm{C}$ (slow) and above $550^{\circ} \mathrm{C}$ (rapid), which is consistent with previous results. However, there is an additional release peak between $\approx 200-350^{\circ} \mathrm{C}$, which has been reproduced in another test, hinting at a different re-vaporization process, probably linked to the nature of the deposit in this temperature range (720$620^{\circ} \mathrm{C}$ ). This new release mechanism may be owed to the Csl deposition temperature which resulted in a non-uniform amorphous like layer of deposits (see section 4.1) which is quite different to aerosol impaction [29] so that one can expect strong evolution at the molecular level too (for instance in the structure of the Csl outermost surface), inducing differences in the reaction mechanism - as will be seen with the DFT calculations (section 5). kinetics for this series of tests is shown starting at $\approx 170-250^{\circ} \mathrm{C}$. 

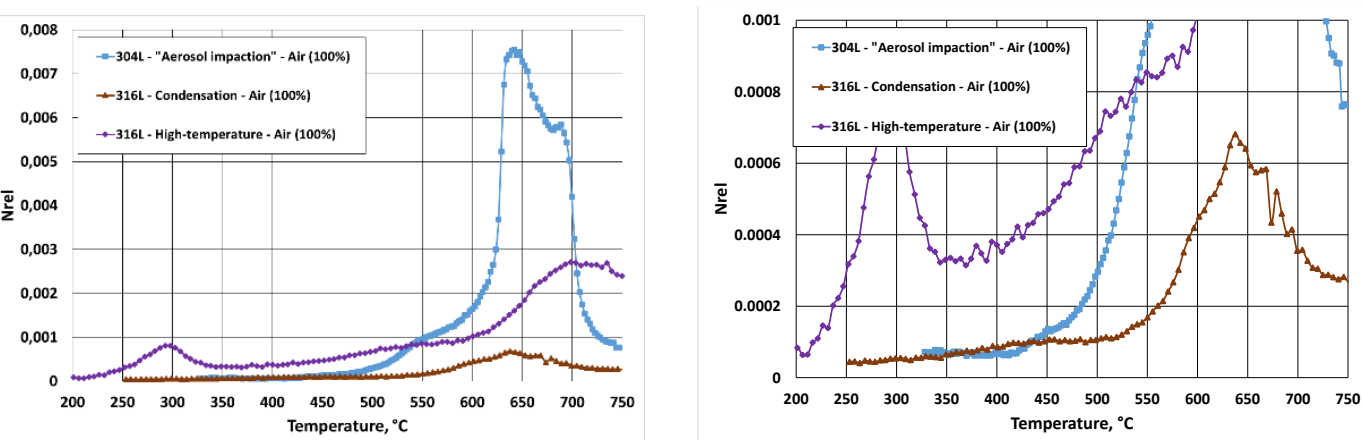

Figure 6. Release and transport kinetics of $\mathrm{I}_{2}$ during re-vaporization of $\mathrm{CsI}$ deposits in pure air with a heating rate of $5^{\circ} \mathrm{C} / \mathrm{min}$ up to $750^{\circ} \mathrm{C}$; blue curve : CSI RT aerosol impaction" (condition 1, air flow rate $53 \mathrm{~mL} / \mathrm{min}$ ), brown curve: CsI vapour condensation (condition 9, air flow rate $200 \mathrm{~mL} / \mathrm{min}$ ); purple curve : $\mathrm{Cs}$ l high-temperature vapour deposition (condition 6, air flow $200 \mathrm{~mL} / \mathrm{min}$ )

\subsubsection{Influence of substrate nature: stainless steel vs. gold inert surface (condition 14)}

A previous study [49] has linked the formation of gaseous molecular iodine to the interaction between $\mathrm{Csl}$ and $\mathrm{Cr}_{2} \mathrm{O}_{3}$ in presence of dioxygen. This assumption is supported by the fact that the reaction cited by Sasaki et al. [49] is thermodynamically favoured in the temperature range of our conditions. In air conditions, our observations (release of $\mathrm{I}_{2}$ and formation of caesium chromate species) allowed us to propose a similar reactivity with the surface [31]. For the further understanding of the phenomenon, it was decided to perform additional tests whose goals were to determine whether there are other mechanisms involved in the formation of $\mathrm{I}_{2}$, besides CsI-substrate interaction.

Consequently, Csl aerosol deposits (aerosol impaction at room temperature) have been generated on a chemically inert surface - gold coupons, and a series of re-vaporization tests in pure air have been performed afterwards (condition $n^{\circ} 14$ ). Integral tests in the RIGolo device have led to the total release of caesium ( $0.4 \%$ detected on the coupon after re-vaporization by ICP-MS) and iodine from the surface of the gold coupon. The $C s / I \approx 1.6$ in the alumina tube, suggesting again the revaporization of CS under other species besides Csl compounds. Up to $28 \%$ of iodine has been released as $\mathrm{I}_{2}$ (relative to the total measured amount of iodine at the end of test), which is lower compared to the re-vaporization from the pre-oxidized $304 \mathrm{~L}$ coupons and $316 \mathrm{~L}$ foils in the same conditions (conditions 1 and 12 respectively). Nevertheless, this lower release may be owed to deposit inhomogeneities. These results suggest that the formation of $I_{2}$ is not due only to the interaction of CsI with the oxide substrate, but that the oxidation of iodide by the gas phase plays an important role in iodine vaporization.

From a kinetic point of view, TGA analysis has shown that the process is initiated at a higher temperature $\left(526^{\circ} \mathrm{C}\right)$ compared to $\mathrm{Cs}$ l re-vaporization onset on $304 \mathrm{~L}$ coupons (see section 4.2.1). Figure 7 shows the gaseous molecular iodine release kinetics and the pattern clearly resembles that of Csl re-vaporization from pre-oxidized stainless steel surface (condition $n^{\circ} 1$ ):

1) A low release between $\approx 450-560^{\circ} \mathrm{C}$;

2) A more important release (up to the depletion of the iodine source) above $560^{\circ} \mathrm{C}$. It is worth noting that this release is slower compared to the release in condition $n^{\circ} 1$. 
This suggests that the mechanisms governing the formation of $I_{2}$ are very close, regardless of the substrate. As a consequence, the role of pre-oxidized stainless steel in the production of gaseous iodine species is less important than initially expected.

Nevertheless, the differences observed between kinetic of $\mathrm{I}_{2}$ productions when considering an inert surface and pre-oxidized stainless steel, indicates that some substrate effect cannot be excluded at high temperature.

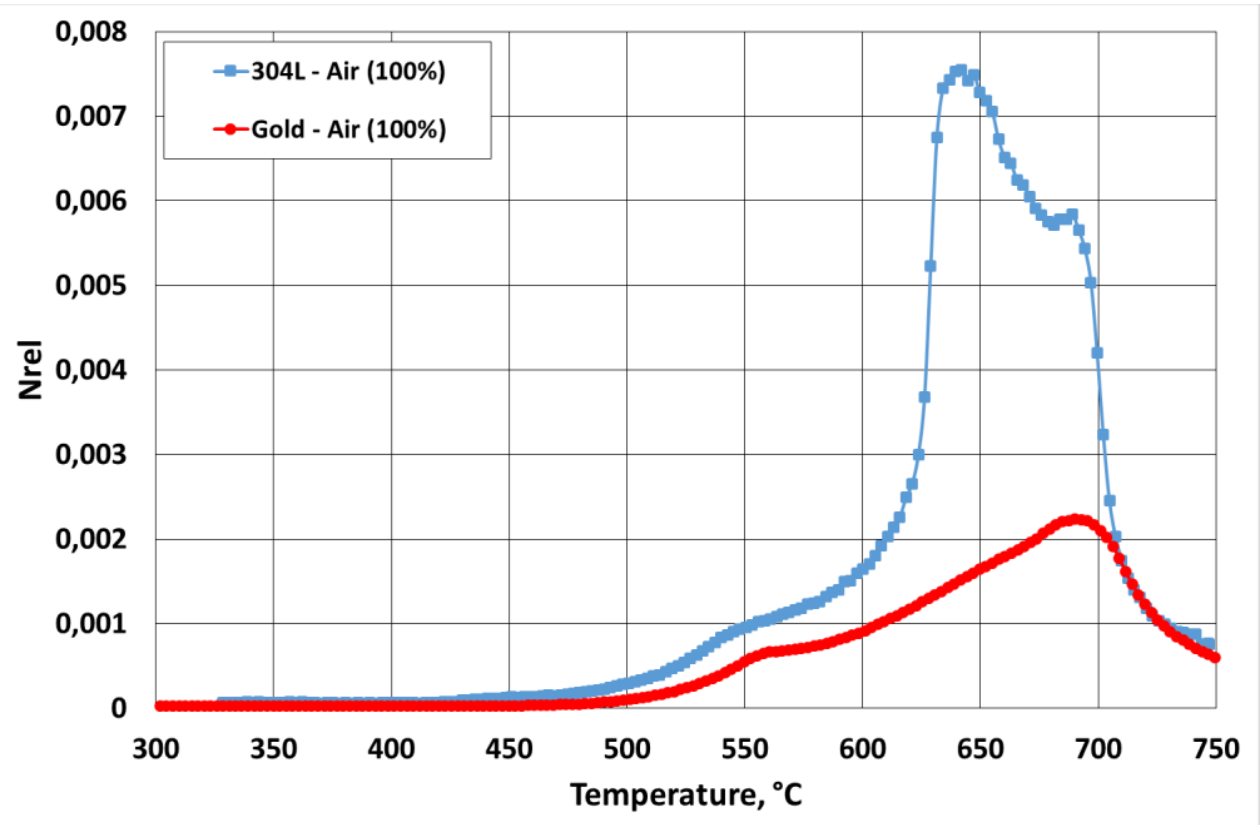

Figure 7. Release and transport kinetics of $\mathrm{I}_{2}$ during re-vaporization of CsI aerosols (RT aerosol impaction) in pure air (53 $53 \mathrm{mLn} / \mathrm{min}$ ) and with a heating rate of $5^{\circ} \mathrm{C} / \mathrm{min}$ up to $750^{\circ} \mathrm{C}$; blue curve: pre-oxidized $304 \mathrm{~L}$ surface ; red curve : gold surface.

\subsubsection{Thermal cycle boundaries : kinetic of $\mathrm{I}_{2}$ release up to $550^{\circ} \mathrm{C}$}

Based on the results of previous online measurement tests, it was decided to conduct another one with a limited maximum temperature of $\approx 550^{\circ} \mathrm{C}$, which is the upper limit for the first step of $\mathrm{I}_{2}$ release. The goal was to study the release phenomenon in the $450-550^{\circ} \mathrm{C}$ range. In order to reduce the carrier gas interference at low temperature, the sample was heated under argon up to $\approx 420^{\circ} \mathrm{C}$, and then the carrier gas was switched to a mixture of air/steam (\% vol. 50/50). Figure 7 shows the $I_{2}$ release and transport kinetics and it can be noticed that the release starts at $\approx 440^{\circ} \mathrm{C}$ and ends just after the final temperature of $\approx 550^{\circ} \mathrm{C}$ is reached, with a subse quent decrease in signal, which is probably due to the depletion of the source involved in this first mechanism. The fine peak at $420^{\circ} \mathrm{C}$ is an artifact in the IBBCEAS response due to a transient overpressure in the IBB CEAS cell when switching the carrier gas composition from argon to the air/steam mix. This transient induced a shit in the baseline which could not be corrected during the test. The $I_{2}$ spectral fingerprint is indeed clearly observed from $450^{\circ} \mathrm{C}$ on.

No integral test in the RIGolo device has been performed in these conditions, but surface characterization by ToF-SIMS of the sample has been done. The depth profile analysis in positive polarity revealed an intense $\mathrm{Cs}^{+}$signal (Figure 8a), while the analysis in negative polarity has revealed the presence of relatively intense ${ }^{-}$' secondary ions (Figure $8 b$ ). Also, the secondary ion clusters 
$\mathrm{Cs}_{2} \mathrm{CrO}_{3}{ }^{+}$and $\mathrm{Cs}_{2} \mathrm{Cr}_{2} \mathrm{O}_{9} \mathrm{H}^{+}$have been detected, which indicates the formation of $\mathrm{Cs}-\mathrm{Cr}-\mathrm{O}$ compounds. All these results suggest that a part of iodine has been released from the surface as $\mathrm{I}_{2}$ and that caesium mainly remained on the surface, both as $\mathrm{Csl}$ and mixed Cs-Cr oxides. Furthermore, it would seem that up to $550^{\circ} \mathrm{C}$ the formation of $\mathrm{I}_{2}$ is based on the reaction between the CsI deposit and carrier gas components in a heterogeneous phase. The most intense release observed above $550^{\circ} \mathrm{C}$ (Figure 3, blue curve) could then be explained by the vaporization of Csl deposits (which starts between 550 and $600^{\circ} \mathrm{C}$ ) followed by a reaction in gaseous (homogeneous) phase, which would favour the contact between Csl and carrier gas molecules. In this latter case, the residual quantity of Cs on the surface would be low as observed in condition 1 (see table 3 ).

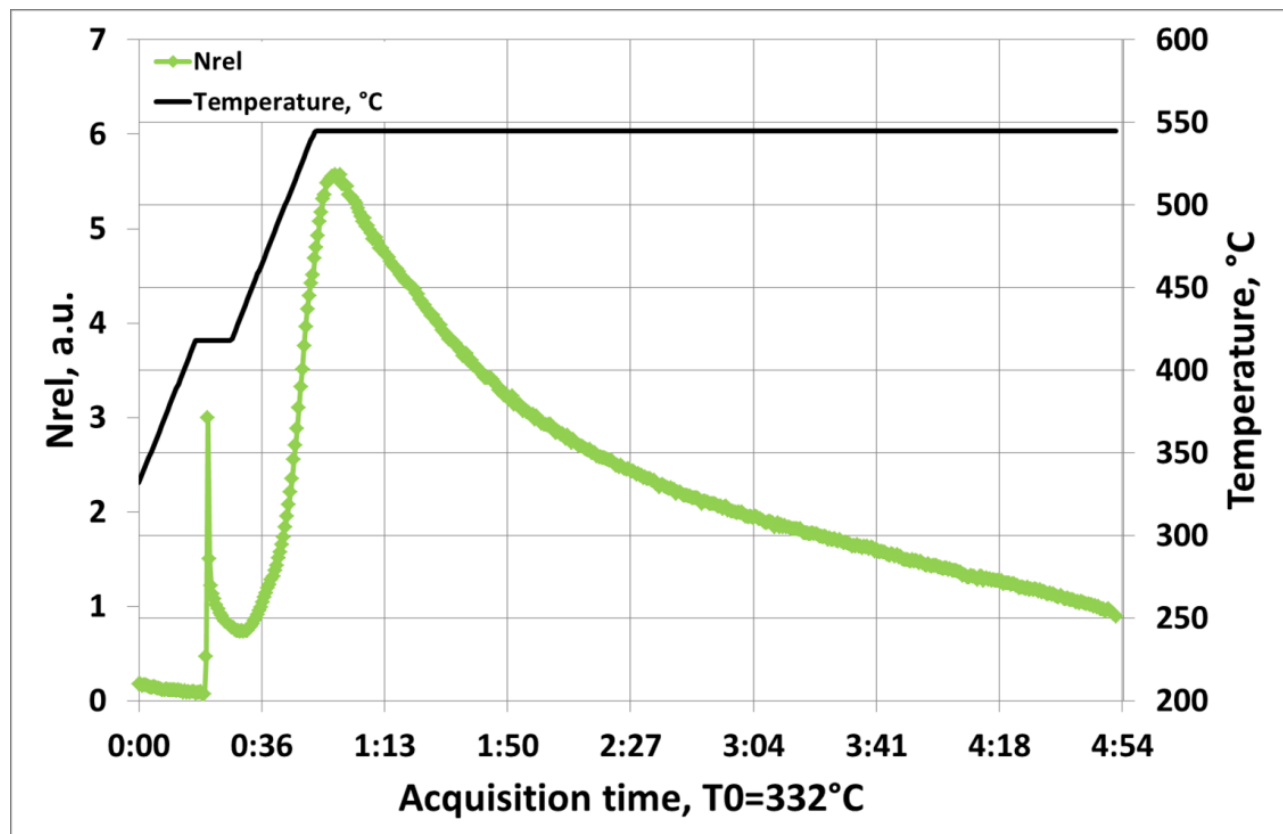



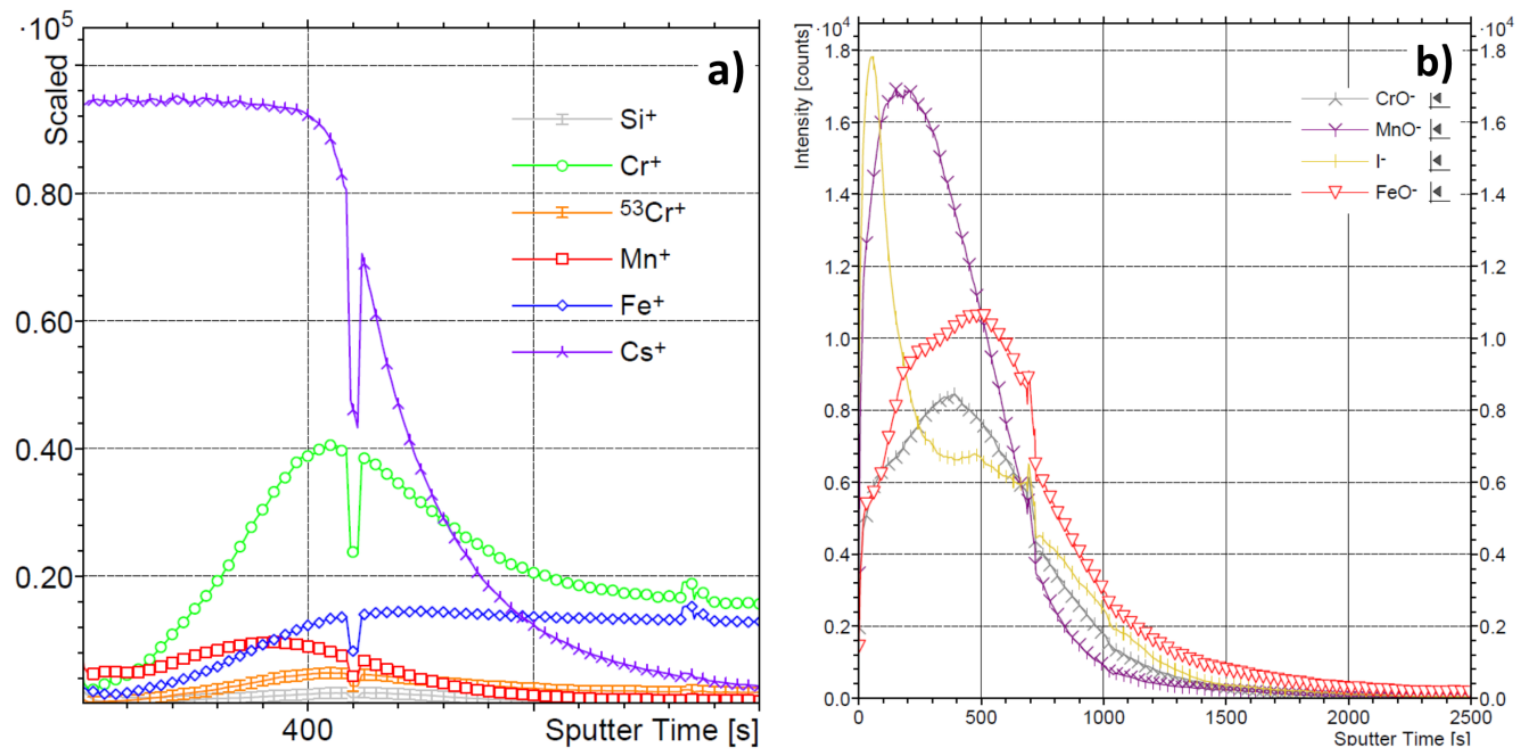

Figure 9. ToF-SIMS depth profile of a CsI aerosol deposit re-vaporized from pre-oxidized 304L coupon: a) secondary ions in positive polarity and b) secondary ions in negative polarity.

\section{Theoretical modelling}

In order to get insight in the molecular mechanism of the Csl revaporisation for small aerosols, we performed DFT modelling of the possible oxygen interaction and reaction on the surface of the CsI Aerosol. The size of the particle deposited in the experiment is large (larger than $1 \mu \mathrm{m})$. The larger part of the CsI particles will not be directly in interaction with the support. Furthermore, the evolution at relatively low temperatures $\left(500-650^{\circ} \mathrm{C}\right)$ is mostly independent of the nature of the support. A theoretical model that does not include explicitly the support will be valid to investigate the Csl surface oxidation mechanism. Furthermore, the reactivity of the deposited Csl depends on the preparation conditions which will modify both the size of the particles and the nature of the exposed surfaces and sites. By defining various models of the Csl surfaces, it will be possible to explain the differences observed experimentally as well as the effect of $\mathrm{O}_{2}$ and water on the surfaces.

\subsection{Model}

Csl crystal has a simple cubicstructure which belongs to the Pm3m group, with two atoms in the unit cell, caesium at $(0,0,0)$ and iodine at $(a / 2)(1,1,1)$ while ' $a$ ' being the lattice constant $(456.67$ $\mathrm{pm}$ )[50] kept fixed in the calculation at the experimental. The nature of the exposed surface is defined by the surface energy of low indexsurfaces. In order to compute them, we define super-cell composed of at least 8 layer of Csl and added $15 \AA$ of vacuum to avoid any interaction between the slab. The four outermost layers have been relaxed. The surface energies of low index surfaces are summarized in table 4.

Table 4 : Surface energy $\left(\mathrm{mJ} . \mathrm{m}^{-2}\right)$ after relaxation of low index surfaces.

\begin{tabular}{|l|l|l|l|l|l|}
\hline Surface index & $(011)$ & $(111)$ & $(210)$ & $(211)$ & $(001)$ \\
\hline Surface energy $\left({\left.\mathrm{mJ} . \mathrm{m}^{-2}\right)}^{193}\right.$ & 520 & 365 & 417 & 615 \\
\hline
\end{tabular}


The (011) surface is the most stable one and considering the large surface energy difference, it will be the only surface exposed by dehydrated CsI particles. The (011) surface is composed of alternating rows of $\mathrm{Cs}$ and I anions.

8

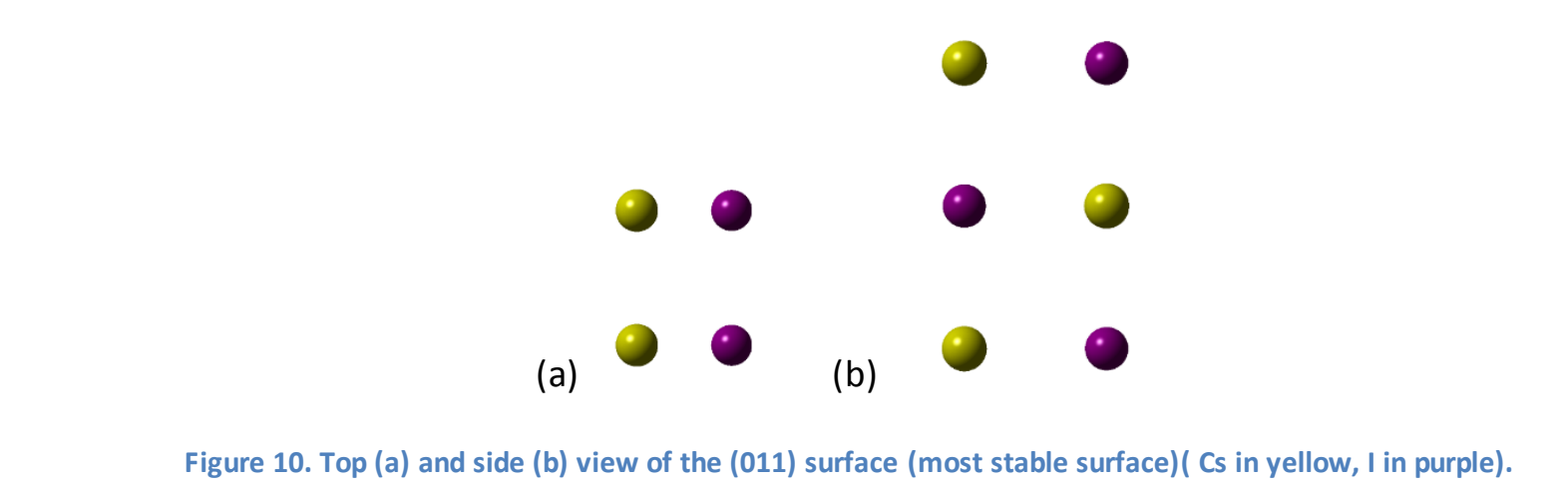

\section{2. $\mathrm{H}_{2} \mathrm{O}$ and $\mathrm{O}_{2}$ Interaction with perfect $(011)$ surfaces.}

The reactive molecules in the gas phase during the experiments are water and dioxygen. We studied theoretically the interaction of these two molecules with the CsI surfaces to determine the reaction that may occur on the surface and may explain the iodine revaporisation.

The water absorption on the surface is molecular. One hydrogen atom of the water molecule forms a hydrogen bond with the surface iodine while the negatively charged oxygen atom interacts with the Cs cation. The $\mathrm{Cs}-\mathrm{O}$ and $\mathrm{H}-\mathrm{I}$ distances are 3.16 and $2.45 \AA$ respectively. The adsorption energy is 0.52 $\mathrm{eV}$. The adsorption is exothermic but as the main interaction is a weak hydrogen bond, the water molecule adsorption will not be favoured at high temperature. We tested the dissociative adsorption of the water molecule on the surface to form both $\mathrm{Cs}-\mathrm{OH}$ and $\mathrm{HI}$ groups. This adsorption is very endothermic $(-3,54 \mathrm{eV})$. The formation of $\mathrm{IH}$ groups on the perfect surface is not possible and such we can exclude the departure of $\mathrm{HI}(\mathrm{g})$ molecule from the surface.

(a)

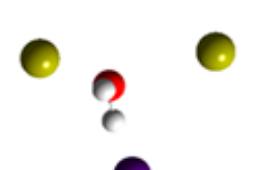

Figure 11. Water adsorption on the perfect (011) surface (a) molecular adsorption (b) dissociative adsorption (Cs in yellow, $\mathrm{I}$ in purple, $\mathrm{O}$ in red, $\mathrm{H}$ in white).

The oxygen molecule adsorption on the surface is also a molecular one. The $\mathrm{O}_{2}$ molecule is located in a $\eta 2$ geometry, on top of one Cs cation. The $\mathrm{O}-\mathrm{Cs}$ distances are $3.04 \mathrm{~A}$ and the $\mathrm{O}-\mathrm{O}$ one is 1.24 very close to the $\mathrm{O}-\mathrm{O}$ distance in the gas phase (. The adsorption is endothermic (Eads $=-0.18 \mathrm{eV}$ ). We study the dissociative adsorption. The oxygen atoms are located in the first surface plane, between Cs and I ion. This adsorption mode is even more endothermic (Eads $=-0.88 \mathrm{eV}$ ) than the molecular one. The oxygen adsorption and reaction with a perfect surface is not probable at high temperature. 
(a)

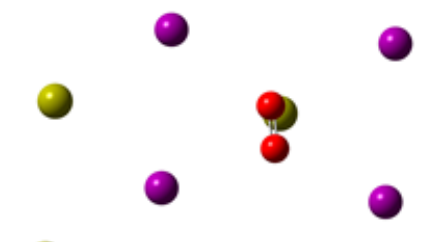

b)

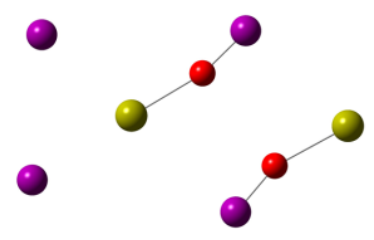
Figure 12. $\mathrm{O}_{2}$ adsorption on the perfect (011) surface (a) molecular adsorption (b) dissociative adsorption ( Cs in
yellow, I in purple, $\mathrm{O}$ in red).

\section{3. $\mathrm{O}_{2}$ interaction with defective surfaces.}

The presence of defects on the surface increases their reactivity. To model these defects, we study the $\mathrm{O}_{2}$ interaction with a step (011) surface: i.e. the (014) surface, composed a step and a (011) terrace (figure 13). The iodine ions located on the step are under-coordinated which would increase their reactivity.

On the opposite to the perfect surface, the oxygen molecular adsorption on the iodine ion located on the step is an exothermic process $(\Delta E=-0,57 \mathrm{eV} /$ Eads $=0.57 \mathrm{eV})$ (b step, figure 14$)$. The oxygen molecule is located between two iodine anions of the edge. The I-O distance is $2.86 \AA$ and the $0-0$ one is $1.27 \AA, 0.04 \AA$ larger than the distance for the gas phase molecule. The oxygen molecule is activated when adsorbed on a defect. The dissociative adsorption is favoured on the edge. The adsorption energy is then $1,07 \mathrm{eV}$ (c step, figure 14). One the oxygen molecule is dissociated on the surface, the desorption of $10^{\circ}$ radical is possible. This final step is endothermic ( $d$ step, figure 14) but will be favoured by a very concentration of iodine in the gas and by the continuous gas flow above the surface. $10^{\circ}$ being a strong oxidant it will react with the iodide to produce $\mathrm{I}_{2(\mathrm{~g})}$ as demonstrated in liquid [51] and in the gas phase[52]. 


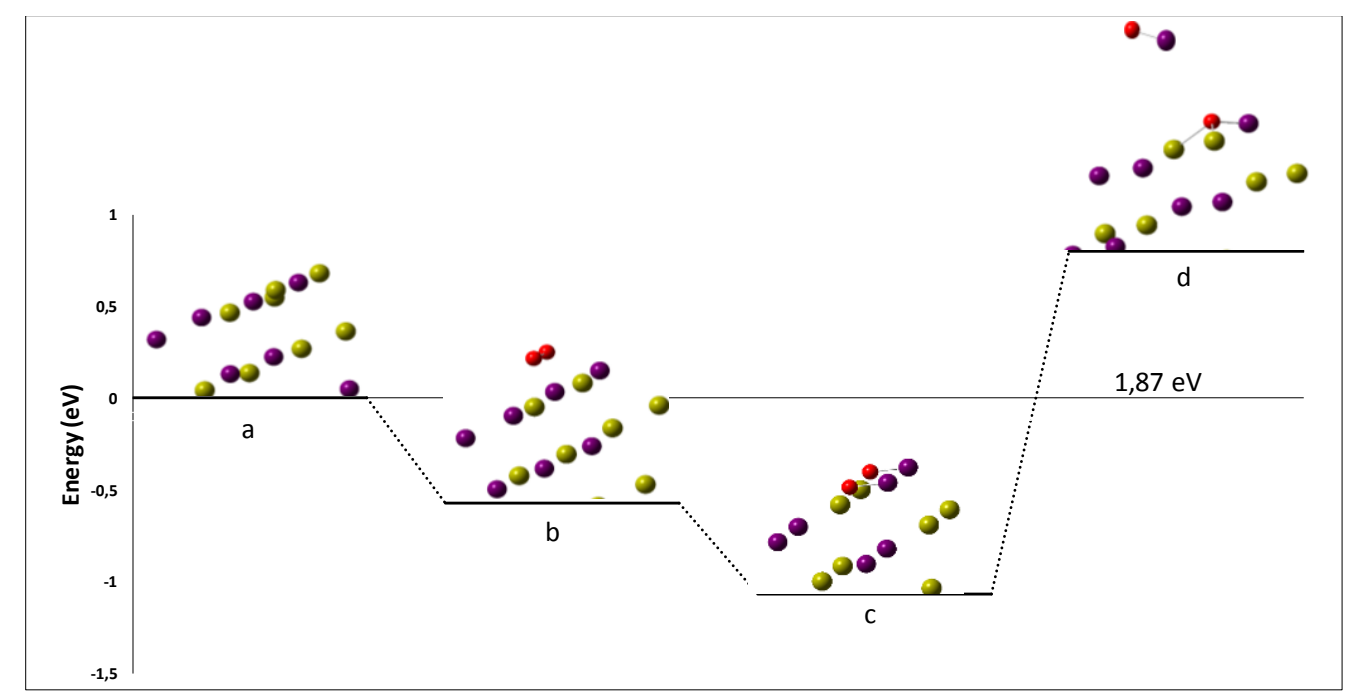

Figure 14. Adsorption and dissociation of $\mathrm{O} 2$ on stepped surface (Cs in yellow, I in purple, $\mathrm{O}$ in red).

In order to get insight in the kinetic of the oxygen molecule dissociation on the surface, we computed the activation energy of the reaction (figure 15$)$. The activation energy is small $\left(E_{\text {act }}=0,64 \mathrm{eV}\right.$ ), which indicate that the surface oxidation will be fast on defects. The O-O distance on the transition state is $1.77 \AA$ A.

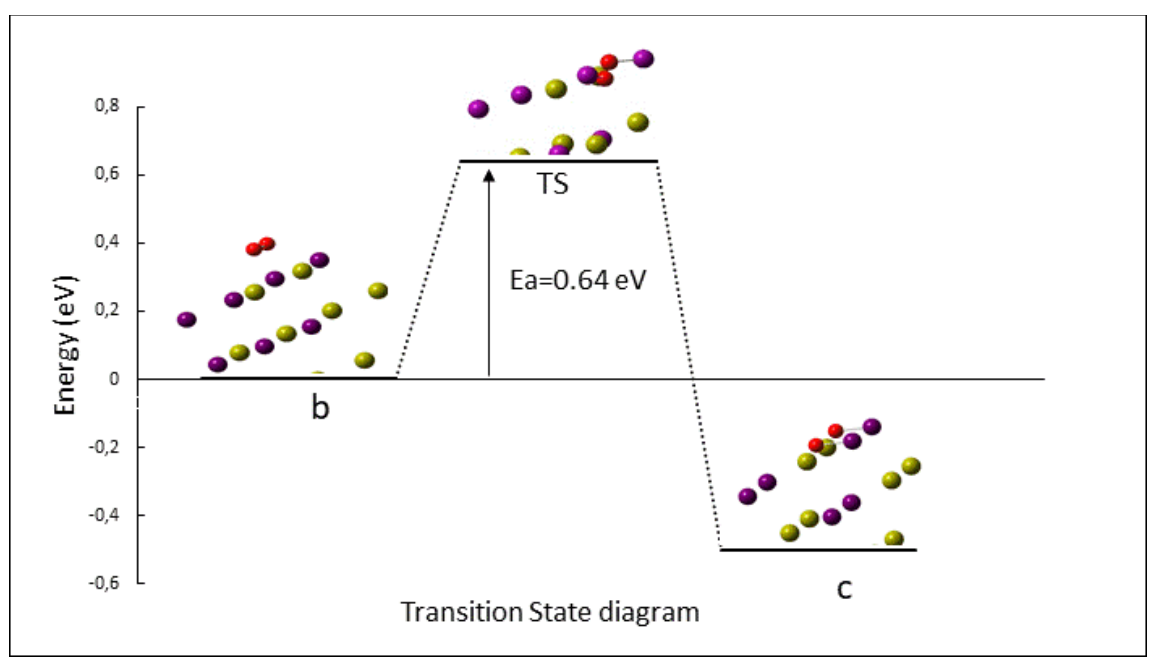

Figure 15. $\mathrm{O}_{2}$ activation mechanism on the step surface ( $C$ s in yellow, I in purple, $\mathrm{O}$ in red).

From the DFT calculation, we can conclude that the water molecule will not be involved directly in the Csl oxidation reactions and in the $\mathrm{I}_{2}$ formation. However, when the quantity of water in the feed is much larger than the oxygen one, the water will have a competitive adsorption on the surface.

On the opposite to water, the $\mathrm{O} 2$ molecules can react on the Csl particles to form in the fi rst step the radical species $10^{\circ}$, but this process will mainly occur on the surface defects. The oxygen reactivity depends then of the nature of the surface and on the numbers of defects. However, once the $10^{\bullet}$ radical have been formed, this reactive species may react with the surface and such create defects on the particle surface. This mechanism may be responsible for the very fast increase of the reaction rate with temperature that is observed experimentally. It may be mentioned that the CsI reactivity at low temperature (around $400^{\circ}$ $\mathrm{C}$ according to the experiments) will depend on the exact nature of the surface and on the 
deposition method. A fast cooling of hot particles on the surface will favour the formation of defects and increased its reactivity.

\section{Conclusion}

From the experimental study, the following trends can be summarized as follows:

- In presence of air, the re-vaporization of CsI deposits from pre-oxidized stainless steel surfaces leads to the release of $45-75 \%$ of $I_{2}$ from initial iodine inventory - except for CsI deposit by vapour condensation. A part of Cs is retained on the surface (2.5-10\% of initial amount) and forms mixed Cs-Cr-O compounds;

- In a mixed air/steam atmosphere, between $12-33 \%$ of iodine is released as $\mathrm{I}_{2}$, regardless of the air content in the carrier gas, the molecular iodine fraction probably depends air content and temperature deposits ;

- The deposit nature (aerosol, high temperature vapour deposition and vapour condensation) does not seem to influence the amount of released molecular iodine strongly or retained caesium. An exception is the Csl deposit by vapour condensation $\left(620-440^{\circ} \mathrm{C}\right)$ which is crystalline and thus has an organized structure;

- The re-vaporization of Csl aerosols from an inert surface (gold) in air leads to the formation of $28 \%$ of molecular iodine (relative to I initial amount), which is lower compared to the revaporization from a stainless steel surface;

- The gaseous molecular iodine release kinetic pattern is generally the same, regardless of carrier gas composition, deposit or substrate nature and consists of two steps: an initial reduced release between $\approx 440-550^{\circ} \mathrm{C}$ and a second rapid release above $550^{\circ} \mathrm{C}$. In the case of Csl high-temperature deposits $\left(720-620^{\circ} \mathrm{C}\right)$ there is an additional $\mathrm{I}_{2}$ release peak between $200-350^{\circ} \mathrm{C}$.

The analysis of these results allows us to make the following conclusions and hypotheses:

- There seem to be several mechanisms responsible for $I_{2}$ formation, depending on the temperature. Below $550^{\circ} \mathrm{C}$ the results suggest a solid-gas (heterogeneous) phase interaction between the deposit and the carrier gas. Above $550^{\circ} \mathrm{C}$, the $\mathrm{Csl}$ starts to vaporize and the interaction is in gas (homogeneous) phase, which would explain the increased rate of $\mathrm{I}_{2}$ release;

- The iodine formation is favoured on the Csl surface defects, and such is influenced by the CsI deposition process. The $I_{2}$ formation start at higher temperature on well crystallized particles. However, the formation of the first $I_{2}$ molecules will induce the formation of defects on the surface which will increase the surface oxidation rate.

To develop some models and cover severe accident boundary conditions, additional experimental investigations are needed to explore other fission products and other gas composition.

\section{Acknowledgements}


761 This work was performed in the frame of the French research program ANR-11-RSNR-0013-01 called 762 MiRE (Mitigation of outside releases in case of nuclear accident), with the financial support of EDF 763 and Framatome. The authors thank the HPC centre of the Lille University for providing CPU 764 resources. Surface analysis have been performed at the 'plateforme d'analyses de surfaces' of the 765 Lille University.

766

767 
1. Cantrel L, Cousin F, Bosland L, et al (2014) ASTECV2 severe acci dent integral code: Fission product modelling and validation. Nuclear Engineering and Design 272:195-206. https://doi.org/10.1016/j.nucengdes.2014.01.011

2. Haste T, Payot F, Bottomley PDW (2013) Transport and deposition in the Phébus FP circuit. Annals of Nuclear Energy 61:102-121. https://doi.org/10.1016/j.anucene.2012.10.032

3. Cantrel L, Albiol T, Bosland L, et al (2018) Research Works on lodine and Ruthenium Behavior in Severe Accident Conditions. Journal of Nuclear Engineering and Radiation Science 4:020903. https://doi.org/10.1115/1.4038223

4. Hidaka A, Igarashi M, Hashimoto K, et al (1995) Experimental and Analytical Study on the Behavior of Cesium lodide Aerosol/Vapor Deposition onto Inner Surface of Pipe Wall under Severe Accident Conditions. Journal of Nuclear Science and Technology 32:1047-1053. https://doi.org/10.1080/18811248.1995.9731813

5. Maruyama Y, Shibazaki H, Igarashi M, et al (1999) Vapor Condensation and Thermophoretic Aerosol Deposition of Cesium lodide in Horizontal Thermal Gradie nt Pipes. Journal of Nuclear Science and Technology 36:433-442. https://doi.org/10.1080/18811248.1999.9726226

6. Girault N, Payot F (2013) Insights into iodine behaviour and speciation in the Phébus primary circuit. Annals of Nuclear Energy 61:143-156. https://doi.org/10.1016/j. anucene.2013.03.038

7. Katata G, Chino M, Kobayashi T, et al (2015) Detailed source term estimation of the atmosphericrelease for the Fukushima Daiichi Nuclear Power Station accident by coupling simulations of an atmospheric dispersion model with an improved deposition scheme and oceanic dispersion model. Atmospheric Chemistry and Physics 15:1029-1070. https://doi.org/10.5194/acp-15-1029-2015

8. Terada H, Katata G, Chino M, Nagai H (2012) Atmospheric discharge and dispersion of radionuclides during the Fukushima Dai-ichi Nuclear Power Plant accident. Part Il: verification of the source term and analysis of regional-scale atmospheric dispersion. Journal of Environmental Radioactivity 112:141-154. https://doi.org/10.1016/j.jenvrad.2012.05.023

9. Anderson, A., Auvinen, A., Bottomley, P., Bryan, C., Freemantle, N., Hieraut, J., Jokiniemi, J., Kingsbury, A., \& Tuson, A. (2000). Revaporisation tests on samples from Phebus fission products: Final report. (Issue 2 ed.) AEA Technology Report, No. AEAT/R/NS/0124

10. Auvinen A, Lehtinen KEJ, Enriquez J, et al (2000) VAPORISATION RATES OF CsOH AND CSI IN CONDITIONS SIMULATING A SEVERE NUCLEAR ACCIDENT. Journal of Aerosol Science 31:10291043. https://doi.org/10.1016/S0021-8502(00)00027-6

11. Bottomley PDW, Knebel K, Van Winckel S, et al (2014) Revaporisation of fission product deposits in the primary circuit and its impact on accident source term. Annals of Nuclear Energy 74:208-223. https://doi.org/10.1016/j.anucene.2014.05.011

12. Knebel K, Bottomley PDW, Rondinella VV, et al (2014) An experimental device to study the revaporisation behaviour of fission product deposits under severe accident conditions. Progress in Nuclear Energy 72:77-82. https://doi.org/10.1016/j.pnucene.2013.07.022 
13. Kalilainen J, KärkeläT, Zilliacus R, et al (2014) Chemical reactions of fission product deposits and iodine transport in primary circuit conditions. Nuclear Engineering and Design 267:140-147. https://doi.org/10.1016/j.nucengdes.2013.11.078

14. Shibazaki H, Maruyama Y, Kudo T, et al (2001) Revaporization of a Csl Aerosol in a Horizontal Straight Pipe in a Severe Accident Condition. Nuclear Technology 134:62-70. https://doi.org/10.13182/NT01-A3186

15. Berdonosov s. s., Sitova m. a. (1997) Chemical Forms of lodine Occurring at Evaporation and Condensation of Cesium lodide in Air. Radiochemistry 39:341-342

16. Berdonosov s. s., Baronov s. b. (1999) Interaction of caesium lodide with an Air Flow at High Temperatures. Radiochemistry 41:63-66

17. Kulyukhin SA, Mikheev NB, Kamenskaya AN, et al (2004) Oxidative Hydrolysis in Water VaporAir Phase of CsI Radioaerosols Produced by CsI Sublimation from Metallic Surface. Radiochemistry 46:63-66. https://doi.org/10.1023/B:RACH.0000024639.33411.68

18. Hijazi H (2017) RÉACTIVITÉ CHIMIQUE DES AÉROSOLS D'IODE EN CONDITIONS ACCIDENTELLES DANS UN RÉACTEUR NUCLÉAIRE. Université de Lille

19. Khanniche S, Louis F, Cantrel L, Černušák I (2017) Investigation of the Reaction Mechanism and Kinetics of lodic Acid with OH Radical Using Quantum Chemistry. ACS Earth and Space Chemistry 1:227-235. https://doi.org/10.1021/acsearthspacechem.7b00038

20. Khanniche S, Louis F, Cantrel L, Černušák I (2017) Thermochemistry of $\mathrm{HIO}_{2}$ Species and Reactivity of lodous Acid with OH Radical: A Computational Study. ACS Earth and Space Chemistry 1:39-49. https://doi.org/10.1021/acsearthspacechem.6b00010

21. Villard A, Khanniche S, Fortin C, et al (2019) A theoretical study of the microhydration processes of iodine nitrogen oxides. International Journal of Quantum Chemistry 119:e25792. https://doi.org/10.1002/qua.25792

22. Khiri D, VandeputteR, Taamalli S, et al (2019) Microhydration of caesium metaborate: structural and thermochemical properties of $\mathrm{CsBO} 2+n \mathrm{H} 2 \mathrm{O}(\mathrm{n}=1-4)$ aggregates. Journal of Molecular Modeling 25:. https://doi.org/10.1007/s00894-019-4094-4

23. Khanniche $S$, Louis F, CantreI L, Černušák I (2016) Computational study of the I2O5+ H2O = 2 HOIO2 gas-phase reaction. Chemical Physics Letters 662:114-119. https://doi.org/10.1016/j.cplett.2016.09.023

24. Khanniche S, Louis F, Cantrel L, Černušák I (2016) A theoretical study of the microhydration of iodic acid (HOIO2). Computational and Theoretical Chemistry 1094:98-107. https://doi.org/10.1016/j.comptc.2016.09.010

25. Khanniche S, Louis F, Cantrel L, Černušák I (2016) A Density Functional Theory and ab Initio Investigation of the Oxidation Reaction of CO by IO Radicals. The Journal of Physical Chemistry A 120:1737-1749. https://doi.org/10.1021/acs.jpca.6b00047

26. Sudolská M, Cantrel L, Budzák Š, Černušák I (2014) Molecular structures and thermodynamic properties of monohydrated gaseous iodine compounds: Modelling for severe accident simulation. Journal of Nuclear Materials 446:73-80. https://doi.org/10.1016/j.jnucmat.2013.11.029 
27. Sudolská M, Cantrel L, Černušák I (2014) Microhydration of caesium compounds: Cs, CsOH, CsI and $\mathrm{Cs} 2 \mathrm{I} 2$ complexes with one to three $\mathrm{H} 2 \mathrm{O}$ molecules of nuclear safety interest. Journal of Molecular Modeling 20:. https://doi.org/10.1007/s00894-014-2218-4

28. Šulková K, Cantrel L, Louis F (2015) Gas-Phase Reactivity of Cesium-Containing Species by Quantum Chemistry. The Journal of Physical Chemistry A 119:9373-9384. https://doi.org/10.1021/acs.jpca.5b05548

29. Taamalli S, Khiri D, Suliman S, et al (2020) Unraveling the Tropospheric Microhydration Processes of lodous Acid HOIO. ACS Earth and Space Chemistry 4:92-100. https://doi.org/10.1021/acsearthspacechem.9b00257

30. Giordano $P$, Auvinen A, Brillant $G$, et al (2010) Recent advances in understanding ruthenium behaviour under air-ingress conditions during a PWR severe accident. Progress in Nuclear Energy 52:109-119. https://doi.org/10.1016/j.pnucene.2009.09.011

31. Obada D., Gasnot L, Mamede A-S, Grégoire A-C (2017) Assessment of medium-term radioactive releases in case of a severe nuclear accident on a Pressurized Water Reactor: experimental study of fission products re-vaporization from deposits (Cs, I). In: Proceedings of ICAPP 2017. Atomic Energy Society of Japan, Fukui and Kyoto (Japan), p 17328

32. Mamede A-S, Nuns N, Cristol A-L, et al (2016) Multitechnique characterisation of 304L surface states oxidized at high temperature in steam and air atmospheres. Applied Surface Science 369:510-519. https://doi.org/10.1016/j.apsusc.2016.01.185

33. Obada D, Mamede A-S, Nuns N, et al (2018) Combined ToF-SIMS and XPS characterization of $304 \mathrm{~L}$ surface after interaction with caesium iodide under PWR severe accident conditions. Applied Surface Science 459:23-31. https://doi.org/10.1016/j.apsusc.2018.07.212

34. Johansson O, Mutelle H, Parker AE, et al (2014) Quantitative IBBCEAS measurements of 12 in the presence of aerosols. Applied Physics B 114:421-432. https://doi.org/10.1007/s00340-0135536-9

35. Obada D (2017) Evaluation de rejets moyen-terme en situation accidentelle grave d'un Réacteurà Eau Pressurisée : étude expérimentale de la re-vaporisation de dépôts de produits de fission ( $C s, I)$. Universitéde Lille

36. Gouello M, Mutelle H, Cousin F, et al (2013) Analysis of the iodine gas phase produced by interaction of $\mathrm{Csl}$ and $\mathrm{MoO} 3$ vapours in flowing steam. Nuclear Engineering and Design 263:462-472. https://doi.org/10.1016/j.nucengdes.2013.06.016

37. Grégoire A-C, Kalilainen J, Cousin F, et al (2015) Studies on the role of molybdenum on iodine transport in the RCS in nuclear severe accident conditions. Annals of Nuclear Energy 78:117129. https://doi.org/10.1016/j.anucene.2014.11.026

38. Bahrini C, Grégoire A-C, Obada D, et al (2018) Incoherent broad-band cavity enhanced absorption spectroscopy for sensitive and rapid molecular iodine detection in the presence of aerosols and watervapour. Optics \& Laser Technology 108:466-479. https://doi.org/10.1016/j.optlastec.2018.06.050

39. $\quad$ vasp.5.4.1 
40. HafnerJ (2008) Ab-initio simulations of materials using VASP: Density-functional theory and beyond. Journal of Computational Chemistry 29:2044-2078. https://doi.org/10.1002/jcc.21057

41. Kresse G, FurthmüllerJ (1996) Efficiency of ab-initio total energy calculations for metals and semiconductors using a plane-wave basis set. Computational Materials Science 6:15-50. https://doi.org/10.1016/0927-0256(96)00008-0

42. Kresse G, Joubert D (1999) From ultrasoft pseudopotentials to the projector augmented-wave method. Physical Review B 59:1758-1775. https://doi.org/10.1103/PhysRevB.59.1758

43. Perdew JP, Burke K, Ernzerhof M (1996) Generalized Gradient Approximation Made Simple. Physical ReviewLetters 77:3865-3868. https://doi.org/10.1103/PhysRevLett.77.3865

44. Methfessel M, Paxton AT (1989) High-precision sampling for Brillouin-zone integration in metals. Physical Review B 40:3616-3621. https://doi.org/10.1103/PhysRevB.40.3616

45. Monkhorst HJ, Pack JD (1976) Special points for Brillouin-zone integrations. Physical Review B 13:5188-5192. https://doi.org/10.1103/PhysRevB.13.5188

46. Tkatchenko A, Scheffler M (2009) Accurate Molecular Van Der Waals Interactions from Ground State Electron Density and Free-Atom Reference Data. Physical Review Letters 102:. https://doi.org/10.1103/PhysRevLett.102.073005

47. Riggs CA, Tompson RV, Ghosh TK, et al (2007) Water Adsorption Isotherms for Charged and Uncharged Cesium lodide Aerosol Particles. Nuclear Technology 157:74-86. https://doi.org/10.13182/NT07-A3803

48. Souvi SMO, Badawi M, Virot F, et al (2017) Influence of water, dihydrogen and dioxygen on the stability of the $\mathrm{Cr} 2 \mathrm{O} 3$ surface: A first-principles investigation. Surface Science 666:44-52. https://doi.org/10.1016/j.susc.2017.08.005

49. Sasaki K, Tanigaki T, Tomohiro Oshima, et al (2013) Microstructure Analysis for Chemical Interaction between Cesium and SUS316 Steel in Fast Breeder Reactor Application. Journal of Energy and Power Engineering 7:716-725. https://doi.org/10.17265/1934-8975/2013.04.014

50. Satpathy S (1986) Electron energy bands and cohesive properties of $\mathrm{CsCl}, \mathrm{CsBr}$, and Csl. Physical Review B 33:8706-8715. https://doi.org/10.1103/PhysRevB.33.8706

51. Sakamoto Y, Yabushita A, Kawasaki M, Enami S (2009) Direct Emission of I ${ }_{2}$ Molecule and IO Radical from the Heterogeneous Reactions of Gaseous Ozone with Aqueous Potassium lodide Solution. J Phys Chem A 113:7707-7713. https://doi.org/10.1021/jp903486u

52. Fortin C, Fèvre-Nollet $\mathrm{V}$, Cousin F, et al (2019) Box modelling of gas-phase atmospheric iodine chemical reactivity in case of a nuclear accident. Atmospheric Environment 214:116838. https://doi.org/10.1016/j.atmosenv.2019.116838 